Check for updates

Cite this: J. Mater. Chem. C, 2021 9, 10899

Received 23rd April 2021

Accepted 2nd July 2021

DOI: $10.1039 / \mathrm{d} 1 \mathrm{tc0} 01885 \mathrm{j}$

rsc.li/materials-c

\title{
Extremely fast triplet formation by charge recombination in a Nile Red/fullerene flexible dyad $\dagger$
}

\author{
Federica Faroldi, ${ }^{a}$ Brunella Bardi, (D) ${ }^{a}$ Irene Tosi, ${ }^{a}$ Sandra Doria, ${ }^{\text {bc }}$ Jacopo Isopi, (D) d \\ Laura Baldini, (iD a Mariangela Di Donato, (iD bc Massimo Marcaccio, iD d \\ Francesco Sansone (iD ${ }^{a}$ and Francesca Terenziani iD *a
}

\begin{abstract}
A donor/acceptor dyad was obtained by linking Nile Red and fullerene to a calix[4]arene scaffold. The dyad was spectroscopically characterized, both with steady-state and ultrafast transient absorption experiments, as well as with electrochemical and spectroelectrochemical techniques. We demonstrate extremely fast and efficient formation of a long-lived excited triplet localized on the fullerene moiety in this system, occurring in about 80 ps in toluene and 220 ps in chloroform. The mechanism of this process is investigated and discussed. The spectroscopic and electrochemical characterization suggests the occurrence of electron transfer from Nile Red to fullerene, leading to the formation of a chargeseparated state. This state lives very briefly and, because of the small interaction between the electron donor and acceptor, promotes a singlet/triplet state mixing, inducing charge recombination and efficient triplet formation.
\end{abstract}

\section{Introduction}

When an electron donor/acceptor system is photoexcited, an excited singlet exciton forms, which can dissociate via charge separation. The formation of a long-lived charge separated (CS) state is crucial for (artificial) photosynthesis or solar cells, such that charge recombination (CR) is often an unwanted process. ${ }^{1}$ Nevertheless, CR can lead to alternative paths that can be of interest for other applications. Most often, photogenerated charges recombine back to a singlet state. However, in specific conditions, triplet formation by CR can occur. ${ }^{1-3}$ This pathway is of particular interest because it allows for the formation of triplet states without the need of the heavy-atom effect to enhance intersystem crossing (ISC). ${ }^{4}$ Easily accessible triplet excited states can be of paramount importance for many applications such as photoinitiated polymerization, ${ }^{5}$ photodynamic therapy, ${ }^{6}$ photovoltaics, ${ }^{1}$ as well as light emitting diodes

\footnotetext{
${ }^{a}$ Department of Chemistry, Life Sciences and Environmental Sustainability, University of Parma, Parco Area delle Scienze 17/a, 43124 Parma, Italy. E-mail: francesca.terenziani@unipr.it

${ }^{b}$ ICCOM-CNR, Via Madonna del Piano 10, 50019 Sesto Fiorentino (FI), Italy

${ }^{c}$ LENS, Via N. Carrara 1, 50019 Sesto Fiorentino (FI), Italy

'Dipartimento di Chimica "Giacomo Ciamician", Università di Bologna,

Via Selmi 2, 40126 Bologna, Italy

$\dagger$ Electronic supplementary information (ESI) available: Synthesis; ${ }^{1} \mathrm{H}$ NMR spectroscopy; computational results; Rehm-Weller analysis; singlet oxygen generation; supplementary transient spectroscopy data. See DOI: 10.1039/d1tc01885j
}

exploiting triplet-triplet upconversion ${ }^{7}$ or thermally-activated delayed fluorescence (TADF). ${ }^{8}$

Triplet formation by CR has been reported for many compact donor/acceptor dyads in which the two moieties are orthogonal to one another, as to be almost decoupled. ${ }^{9-17}$ In these systems, because of their geometry, CR is accompanied by a change in molecular orbital angular momentum, which can be compensated by a change in the electron spin angular momentum, in the so-called spin-orbit charge transfer ISC (SOCT-ISC) mechanism. ${ }^{1,2}$

Another mechanism to produce triplet states from CS states is the so-called radical pair intersystem crossing (RP-ISC). In this case, the singlet radical pair forming the CS state is converted into a triplet radical pair which subsequently recombines to a neutral triplet state. ${ }^{1,2}$ For this pathway to occur, the spatial overlap between the molecular orbitals of the donor and acceptor species must be tiny. In fact, a small exchange interaction reduces the energy gap between the ${ }^{1} \mathrm{CS}$ and ${ }^{3} \mathrm{CS}$ states, facilitating their mixing and hence activating the RP-ISC pathway. ${ }^{4}$ When the ${ }^{3} \mathrm{CS}$ state is populated via RP-ISC, the spin-selective CR to produce a localized triplet state is significant, so that, typically, short-lived CS states are observed. ${ }^{2}$ RP-ISC was observed for many electron donor/acceptor polyads with large separation distance between the electron donor and acceptor units..$^{10,12,17-21}$

Typically, relatively slow rates of triplet CR $\left(<10^{8} \mathrm{~s}^{-1}\right)$ have been reported for the RP-ISC pathway, while substantially faster rates $\left(>10^{9}\right.$, up to $\left.2.5 \times 10^{10} \mathrm{~s}^{-1}\right)$ have been correlated to the 

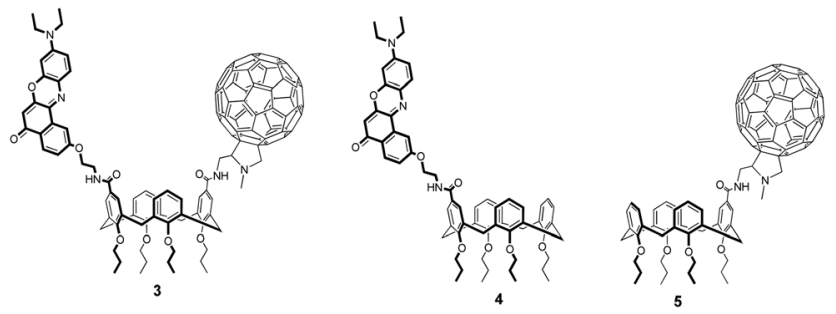

Fig. 1 Structures of the investigated compounds.

SOCT-ISC mechanism. ${ }^{1}$ However, distinguishing between the two mechanisms is not easy and would require time-resolved electron paramagnetic resonance (TREPR). ${ }^{2}$

Moreover, regardless of the mechanism, an important dependence of the triplet formation by CR has been reported not only according to the donor/acceptor strength, distance and orientation, but also to the polarity of the solvent. ${ }^{20,22-24}$

In this paper, we report the synthesis and characterization of a donor/acceptor dyad (3) where the donor moiety is constituted by Nile Red (NR) and the acceptor by $\mathrm{C}_{60}$, both anchored to the upper rim of a calix[4]arene scaffold (Fig. 1, also showing the reference donor (4) and acceptor (5) compounds).

Calix[4]arenes are ideal scaffolds for the preparation of chromophoric dyads designed for the study of energy/charge transfer phenomena. ${ }^{25-29}$ The orientation, mutual distance and conformational freedom of the dyes can be accurately tuned thanks to (i) the availability of four different configurations (cone, partial cone, 1,2-alternate and 1,3-alternate) of the calixarene scaffold, ${ }^{30}$ which project the substituents in different directions; $;^{31,32}$ (ii) the possibility of finely modulating the residual flexibility of the scaffold thanks to the lower rim functionalization; ${ }^{31-34}$ (iii) the possibility of attaching the dyes directly to the aromatic rings of the macrocycle ${ }^{35}$ or through linkers of different rigidity/flexibility. ${ }^{31,32}$

In our system the two dyes are linked to a flexible tetraalkylated cailx[4]arene scaffold through short but flexible linkers in order to endow the dyad of enough conformational freedom to allow the chromophores to get in close contact.

While the dyad was designed to perform charge transfer, we observed an even more interesting behavior upon selective photoexcitation of Nile Red, leading to the very fast formation of a triplet state localized on $\mathrm{C}_{60}$. Other covalent or supramolecular fully organic donor/acceptor dyads comprising fullerene were reported in the literature, ${ }^{20,21,23,36-41}$ and some of them were able to form the fullerene triplet after photoexcitation of the donor. ${ }^{20,21,23,40,41}$ To the best of our knowledge, however, our system is peculiar in terms of the impressive speed of formation of the triplet $\left(\sim 10^{10} \mathrm{~s}^{-1}\right)$, as well as of the little importance of the solvent polarity on the dynamics of the process.

\section{Experimental}

\section{General methods}

Dry solvents were prepared according to standard procedures, distilled before use and stored over 3 or $4 \AA$ molecular sieves.
Most of the solvents and reagents were obtained from commercial sources and used without further purification. Analytical TLC was performed using prepared plates of silica gel (Merck 60 F-254 on aluminum). Merck silica gel 60 (70230 mesh) was used for flash chromatography and for preparative TLC plates. ${ }^{1} \mathrm{H}$ and ${ }^{13} \mathrm{C}$ NMR spectra were recorded on a Bruker AV400 spectrometer. All chemical shifts are reported in part per million (ppm) using the residual peak of the deuterated solvent, whose values are referred to tetramethylsilane (TMS, $\delta_{\mathrm{TMS}}=0$ ), as internal standard. All ${ }^{13} \mathrm{C}$ NMR spectra were performed with proton decoupling. Mass spectra were recorded in ESI mode on a single quadrupole instrument SQ Detector, Waters (capillary voltage $3.7 \mathrm{kV}$, cone voltage $30-160 \mathrm{eV}$, extractor voltage $3 \mathrm{eV}$, source block temperature $80^{\circ} \mathrm{C}$, desolvation temperature $150{ }^{\circ} \mathrm{C}$, cone and desolvation gas $\left(\mathrm{N}_{2}\right)$ flow rates 1.6 and $8 \mathrm{~L} \mathrm{~min}^{-1}$, respectively).

2-(2-Aminoethoxy)-9-diethylamino-5 $H$-benzo[ $\alpha]$ phenoxazin-5one $\left(\mathbf{N R}-\mathbf{N H}_{2}\right),{ }^{32} \quad 25,26,27,28$-tetra- $n$-propoxycalix[4] arene-5,17dicarboxylic acid $(\mathbf{1})^{42}$ and compound $\mathbf{4}^{32}$ were synthesized according to a literature procedure.

\section{Synthesis}

Compound 2. To a solution of $\mathbf{1}(242 \mathrm{mg}, 0.36 \mathrm{mmol})$ in dry DCM $(35 \mathrm{~mL})$, oxalyl chloride $(931 \mu \mathrm{L}, 10.68 \mathrm{mmol})$ was added, together with few drops of dry DMF. The mixture was stirred for 5 hours at room temperature under nitrogen atmosphere and the solvent removed at reduced pressure. The diacyl chloride thus obtained was immediately added to a stirred solution of NR-NH $\mathbf{2}_{\mathbf{2}}(148 \mathrm{mg}, 0.39 \mathrm{mmol}), 2,2$-diethoxyethanamine ( $57 \mu \mathrm{L}$, $0.39 \mathrm{mmol})$ and DIPEA $(0.84 \mathrm{~mL}, 4.81 \mathrm{mmol})$ in dry DCM $(30 \mathrm{~mL})$ and the purple mixture stirred overnight at room temperature under nitrogen. The reaction was quenched with $1 \mathrm{M} \mathrm{HCl}(35 \mathrm{~mL})$ and the organic layer separated. The aqueous phase was extracted with DCM and the combined organic layers were washed twice with deionized water and concentrated under pressure. The residue was purified by column chromatography (DCM/MeOH 9/1) to give the desired compound 2 as a purple solid in $47 \%$ yield $(196 \mathrm{mg}, 0.17 \mathrm{mmol}) .{ }^{1} \mathrm{H}$ NMR $\left(400 \mathrm{MHz}, \mathrm{CDCl}_{3}\right) \delta(\mathrm{ppm}): 8.28$ (d, $\left.J=8.7 \mathrm{~Hz}, 1 \mathrm{H}, \mathrm{ArH}-\mathrm{NR}\right)$, $8.14(\mathrm{~d}, J=2.6 \mathrm{~Hz}, 1 \mathrm{H}$, ArH-NR), 7.65 (d, $J=9.1 \mathrm{~Hz}, 1 \mathrm{H}$, ArH-NR), 7.25 (dd, $J=8.8,2.6 \mathrm{~Hz}, 1 \mathrm{H}, \mathrm{ArH}-\mathrm{NR}), 7.12(\mathrm{~s}, 2 \mathrm{H}, \mathrm{ArH}), 7.11(\mathrm{~s}$, $2 \mathrm{H}, \mathrm{ArH}), 6.69$ (dd, $J=9.1,2.7 \mathrm{~Hz}, 1 \mathrm{H}, \mathrm{ArH}-\mathrm{NR}), 6.61-6.56(\mathrm{~m}$, $6 \mathrm{H}, \mathrm{ArH}), 6.49(\mathrm{~d}, J=2.7 \mathrm{~Hz}, 1 \mathrm{H}, \mathrm{ArH}-\mathrm{NR}), 6.40(\mathrm{t}, J=6.0 \mathrm{~Hz}, 1 \mathrm{H}$, $\left.\mathrm{NHCH}_{2} \mathrm{CH}_{2} \mathrm{O}\right), 6.34(\mathrm{~s}, 1 \mathrm{H}, \mathrm{ArH}-\mathrm{NR}), 6.12(\mathrm{t}, J=5.8 \mathrm{~Hz}, 1 \mathrm{H}$, $\left.\mathrm{NHCH} \mathrm{CH}_{2} \mathrm{CH}\right), 4.62\left(\mathrm{t}, J=5.5 \mathrm{~Hz}, 1 \mathrm{H}, \mathrm{CH}\left(\mathrm{OCH}_{2} \mathrm{CH}_{3}\right)_{2}\right), 4.48(\mathrm{~d}, J=$ $\left.13.4 \mathrm{~Hz}, 2 \mathrm{H}, \operatorname{ArCH} \mathrm{H}_{\mathrm{ax}} \mathrm{Ar}\right), 4.46\left(\mathrm{~d}, J=13.4 \mathrm{~Hz}, 2 \mathrm{H}, \mathrm{ArCH} \mathrm{H}_{\mathrm{ax}} \mathrm{Ar}\right)$, $4.36\left(\mathrm{t}, J=5.1 \mathrm{~Hz}, 2 \mathrm{H}, \mathrm{CH}_{2}\right), 3.94-3.82\left(\mathrm{~m}, 10 \mathrm{H}, \mathrm{OCH}_{2} \mathrm{CH}_{2} \mathrm{CH}_{3}\right.$ and $\left.\mathrm{CH}_{2}\right), 3.80-3.72\left(\mathrm{~m}, 2 \mathrm{H}, \mathrm{OCHHCH}_{3}\right), 3.65-3.56(\mathrm{~m}, 2 \mathrm{H}$, OCH $\left.\mathrm{CCH}_{3}\right), 3.55-3.47\left(\mathrm{~m}, 6 \mathrm{H}, \mathrm{NCH}_{2} \mathrm{CH}_{3}\right.$ and $\left.\mathrm{NHCH}_{2} \mathrm{CH}\right), 3.21$ (d, $\left.J=13.4 \mathrm{~Hz}, 2 \mathrm{H}, \operatorname{ArCH} \mathrm{H}_{\mathrm{eq}} \mathrm{Ar}\right), 3.20(\mathrm{~d}, J=13.4 \mathrm{~Hz}, 2 \mathrm{H}$, $\left.\mathrm{ArCH} \mathrm{H}_{\mathrm{eq}} \mathrm{Ar}\right), 2.00-1.85\left(\mathrm{~m}, 8 \mathrm{H}, \mathrm{OCH}_{2} \mathrm{CH}_{2} \mathrm{CH}_{3}\right), 1.33-1.23(\mathrm{~m}$, $12 \mathrm{H}, \mathrm{CH}\left(\mathrm{OCH}_{2} \mathrm{CH}_{3}\right)_{2}$ and $\left.\mathrm{NCH}_{2} \mathrm{CH}_{3}\right), 1.06-0.94(\mathrm{~m}, 12 \mathrm{H}$, $\left.\mathrm{OCH}_{2} \mathrm{CH}_{2} \mathrm{CH}_{3}\right) \cdot{ }^{13} \mathrm{C}$ NMR (100 MHz, $\left.\mathrm{CDCl}_{3}\right) \delta(\mathrm{ppm}): 190.7$, 183.2, 167.9, 161.3, 159.7, 156.1, 150.8, 146.9, 140.1, 135.7, $134.3,134.2,131.2,128.7,128.4,128.3,128.1,127.9,127.7$, 127.2 , 127.0, 126.9, 124.8, 122.6, 122.4, 118.2, 109.6, 106.9, 
105.3, 100.9, 100.8, 96.3, 76.7, 72.4, 67.3, 62.8, 55.2, 45.1, 42.2, $39.4,32.2,30.9,29.7,29.3,23.1,22.7,15.5,14.1,12.6,10.3$, 10.24, 10.15. ESI-MS: $m / z$ calcd for $\mathrm{C}_{70} \mathrm{H}_{82} \mathrm{~N}_{4} \mathrm{O}_{11} \mathrm{Na}\left[(2+\mathrm{Na})^{+}\right]$ 1177.6, found $1178.2(100 \%)$; calcd for $\mathrm{C}_{70} \mathrm{H}_{82} \mathrm{~N}_{4} \mathrm{O}_{11} \mathrm{~K}\left[(2+\mathrm{K})^{+}\right]$ 1193.7, found $1194.3(40 \%)$.

Compound 6. After dissolving calixarene 2 (150 mg, $0.13 \mathrm{mmol})$ in 1,4-dioxane $(20 \mathrm{~mL}), 1 \mathrm{M} \mathrm{HCl}(20 \mathrm{~mL})$ was added and the mixture allowed to stir at room temperature. After 4 hours, DCM $(30 \mathrm{~mL})$ and $\mathrm{H}_{2} \mathrm{O}(15 \mathrm{~mL})$ were added to the flask and the two phases separated. The aqueous layer was extracted twice with DCM and the organic phases were reunited and washed twice with water $(2 \times 60 \mathrm{~mL})$ to neutral $\mathrm{pH}$, then concentrated under reduced pressure. The residue was purified by column chromatography (DCM/acetone 85/15) to afford the desired compound as a purple solid (108 $\mathrm{mg}, 0.10 \mathrm{mmol}, 77 \%$ yield). ${ }^{1} \mathrm{H}$ NMR (400 MHz, $\left.\mathrm{CDCl}_{3}\right) \delta$ (ppm): 9.66 (s, 1H, CHO), 8.27 (d, $J=8.7 \mathrm{~Hz}, 1 \mathrm{H}, \operatorname{ArH}-\mathrm{NR}), 8.12$ (s, 1H, ArH-NR), 7.65 (d, $J=$ $9.1 \mathrm{~Hz}, 1 \mathrm{H}, \mathrm{ArH}-\mathrm{NR}), 7.22$ (d, $J=8.9 \mathrm{~Hz}, 1 \mathrm{H}, \operatorname{ArH}-\mathrm{NR}), 7.01$ (s, 2H, ArH), 6.96 (s, 2H, ArH), 6.81-6.67 (m, 8H, ArH-NR, 6xArH and $\mathrm{NHCH}_{2} \mathrm{CH}$ ), 6.49 (s, 1H, ArH-NR), 6.34 (br s, $\mathrm{NHCH}_{2} \mathrm{CH}_{2} \mathrm{O}$ and ArH-NR), 4.48 (d, $J=13.4 \mathrm{~Hz}, 2 \mathrm{H}, \mathrm{ArCHH} \mathrm{ax}_{\mathrm{ar}} \mathrm{Ar}, 4.46$ (d, $J=$ $\left.13.4 \mathrm{~Hz}, 2 \mathrm{H}, \mathrm{ArCH} \mathrm{H}_{\mathrm{ax}} \mathrm{Ar}\right), 4.32\left(\mathrm{t}, J=5.1 \mathrm{~Hz}, 2 \mathrm{H}, \mathrm{CH}_{2}\right), 4.20(\mathrm{~d}$, $\left.J=4.9 \mathrm{~Hz}, 2 \mathrm{H}, \mathrm{CH}_{2} \mathrm{CHO}\right), 3.95-3.78\left(\mathrm{~m}, 10 \mathrm{H}, \mathrm{OCH}_{2} \mathrm{CH}_{2} \mathrm{CH}_{3}\right.$ and $\mathrm{CH}_{2}$ ), 3.50 (q, $\left.J=6.9 \mathrm{~Hz}, 4 \mathrm{H}, \mathrm{NCH}_{2} \mathrm{CH}_{3}\right), 3.23(\mathrm{~d}, J=13.4 \mathrm{~Hz}, 2 \mathrm{H}$, $\left.\mathrm{ArCHH}_{\mathrm{eq}} \mathrm{Ar}\right), 3.20$ (d, $\left.J=13.4 \mathrm{~Hz}, 2 \mathrm{H}, \mathrm{ArCHH}_{\mathrm{eq}} \mathrm{Ar}\right), 2.00-1.85$ (m, $8 \mathrm{H}, \mathrm{OCH}_{2} \mathrm{CH}_{2} \mathrm{CH}_{3}$ ), 1.29 (t, $\left.J=6.6 \mathrm{~Hz}, 6 \mathrm{H}, \mathrm{NCH}_{2} \mathrm{CH}_{3}\right), 1.07-0.95$ $\left(\mathrm{m}, 12 \mathrm{H}, \mathrm{OCH}_{2} \mathrm{CH}_{2} \mathrm{CH}_{3}\right) .{ }^{13} \mathrm{C}$ NMR $\left(100 \mathrm{MHz}, \mathrm{CDCl}_{3}\right) \delta(\mathrm{ppm})$ : $197.7,183.2$, 168.2, 168.0, 161.3, 159.6, 159.5, 156.5, 152.1, $150.8,146.9,139.8,135.3,134.8,134.1,131.2,128.6,127.97$, 127.86, 127.6, 127.1, 126.9, 125.9, 124.8, 122.6, 118.2, 109.6, 106.8, 105.3, 96.3, 67.3, 50.5, 45.1, 39.3, 31.9, 30.9, 29.7, 29.4, 23.3, 23.2, 22.7, 14.1, 12.6, 10.4, 10.2. ESI-MS: $\mathrm{m} / \mathrm{z}$ calcd for $\mathrm{C}_{66} \mathrm{H}_{72} \mathrm{~N}_{4} \mathrm{O}_{10} \mathrm{Na}\left[(6+\mathrm{Na})^{+}\right]$1103.5, found 1103.5 (100\%); calcd for $\mathrm{C}_{66} \mathrm{H}_{72} \mathrm{~N}_{4} \mathrm{O}_{10} \mathrm{~K}\left[(6+\mathrm{K})^{+}\right]$1119.6, found 1120.9 (30\%).

Nile Red- $\mathrm{C}_{60}$ calix[4] arene (3). To a solution of $6(102 \mathrm{mg}$, $0.094 \mathrm{mmol})$ in dry toluene $(20 \mathrm{~mL}), N$-methylglycine $(17 \mathrm{mg}$, $0.19 \mathrm{mmol})$ and fullerene $\mathrm{C}_{60}(68 \mathrm{mg}, 0.094 \mathrm{mmol})$ were added and the mixture heated to reflux for 3 hours, after which the solvent was evaporated under vacuum. The residue was dissolved in DCM and washed twice with water, then the DCM evaporated at reduced pressure. The product was purified by column chromatography (DCM/MeOH 98/2) and then preparative TLC plates (DCM/MeOH 98:2) to give a purple solid in $23 \%$ yield (40 mg, $0.022 \mathrm{mmol})$. M.p.: > $300{ }^{\circ} \mathrm{C} .{ }^{1} \mathrm{H}$ NMR $(400 \mathrm{MHz}$, $\left.\mathrm{CDCl}_{3}\right) \delta(\mathrm{ppm}): 8.29$ (d, $\left.J=8.7 \mathrm{~Hz}, 1 \mathrm{H}, \operatorname{ArH}-\mathrm{NR}\right), 8.15$ (d, $J=$ $2.6 \mathrm{~Hz}, 1 \mathrm{H}, \operatorname{ArH}-\mathrm{NR}), 7.63$ (d, $J=9.1 \mathrm{~Hz}, 1 \mathrm{H}, \operatorname{ArH}-\mathrm{NR}), 7.25$ (d, $J=$ $2.6 \mathrm{~Hz}, 1 \mathrm{H}, \mathrm{ArH}-\mathrm{NR}$ ), 7.17 (s, 1H, ArHCO), 7.05 (s, 1H, ArHCO), 6.98 (s, 2H, ArHCO) 6.82 (br s, $1 \mathrm{H}, \mathrm{NHCH}_{2} \mathrm{CH}$ ), 6.73 (br s, $1 \mathrm{H}$, ArH), 6.57-6.49 (m, 5H, 4xArH and ArH-NR), $6.53(\mathrm{t}, J=7.4 \mathrm{~Hz}$, $1 \mathrm{H}, \mathrm{ArH}), 6.48$ (d, $J=2.7 \mathrm{~Hz}, 1 \mathrm{H}, \mathrm{ArH}-\mathrm{NR}), 6.37$ (t, $J=5.5 \mathrm{~Hz}, 1 \mathrm{H}$, $\mathrm{NHCH}_{2} \mathrm{CH}_{2}$ ), 6.34 (s, 1H, ArH-NR), 4.94 (d, $J=9.5 \mathrm{~Hz}, 1 \mathrm{H}$, $\mathrm{CH}_{3} \mathrm{NCHH}$ ), 4.69 (d, $\left.J=12.8,6.7 \mathrm{~Hz}, 1 \mathrm{H}, \mathrm{NHCHH}\right), 4.52-4.40$ $\left(\mathrm{m}, 4 \mathrm{H}, \mathrm{ArCH} \mathrm{H}_{\mathrm{ax}} \mathrm{Ar}\right), 4.39-4.30\left(\mathrm{~m}, 2 \mathrm{H}, \mathrm{CH}_{2}\right), 4.23(\mathrm{~d}, J=9.5 \mathrm{~Hz}$, $1 \mathrm{H}, \mathrm{CH}_{3} \mathrm{NCH} H$ ), 4.12 (br s, 1H, $\mathrm{NHCHH}$ ), 4.09 (br s, $1 \mathrm{H}$, $\mathrm{NHCH}_{2} \mathrm{CH}$ ), 3.96 (br s, $1 \mathrm{H}, \mathrm{CH}_{2}$ ), 3.90-3.79 (m, 9H, $\mathrm{OCH}_{2}$ and $\mathrm{CH}_{2}$ ), 3.49 (q, $\left.J=7.1 \mathrm{~Hz}, 4 \mathrm{H}, \mathrm{NCH}_{2} \mathrm{CH}_{3}\right), 3.29-3.12(\mathrm{~m}, 4 \mathrm{H}$,
ArCH $\left.\mathrm{H}_{\mathrm{eq}} \mathrm{Ar}\right), \quad 3.02\left(\mathrm{~s}, \quad 3 \mathrm{H}, \quad \mathrm{NCH}_{3}\right), \quad 1.97-1.84(\mathrm{~m}, \quad 8 \mathrm{H}$, $\left.\mathrm{OCH}_{2} \mathrm{CH}_{2} \mathrm{CH}_{3}\right), 1.28\left(\mathrm{t}, J=7.0 \mathrm{~Hz}, 6 \mathrm{H}, \mathrm{NCH}_{2} \mathrm{CH}_{3}\right), 1.04-0.96$ (m, $\left.\left.12 \mathrm{H}, \mathrm{OCH}_{2} \mathrm{CH}_{2} \mathrm{CH}_{3}\right) .{ }^{13} \mathrm{C} \mathrm{NMR} \mathrm{(100} \mathrm{MHz,} \mathrm{CDCl}_{3}\right) \delta(\mathrm{ppm})$ : 183.2, 167.2, 161.4, 159.5, 156.5, 155.9, 154.3, 153.3, 152.7, 150.8, $147.3,146.3,146.2,146.1,145.9,145.6,145.5,145.4,145.26$, 145.25, 145.20, 145.1, 144.64, 144.60, 144.4, 144.3, 143.1, 142.6, 142.5, 142.15, 142.10, 142.07, 141.9, 141.7, 141.6, 140.2, 140.1, 139.9, 139.8, 136.0, 135.7, 135.4, 135.3, 135.1, 134.7, 134.1, 131.2, 128.7, 128.5, 128.1, 127.8, 127.4, 127.3, 127.2, 126.9, 126.6, 125.9, $124.8,122.5,122.3,118.3,109.6,106.9,105.3$, 96.3, 73.9, 70.0, 69.4, 67.5, 45.1, 39.5, 39.4, 37.5, 31.1, 31.0, 29.7, 23.3, 23.2, 23.1, 12.6, 10.39, 10.36, 10.2, 7.1. ESI-MS: $m / z$ calcd for $\mathrm{C}_{128} \mathrm{H}_{78} \mathrm{~N}_{5} \mathrm{O}_{9}$ $\left[(3+\mathrm{H})^{+}\right]$1828.6, found $1830.2(40 \%)$; calcd for $\mathrm{C}_{128} \mathrm{H}_{79} \mathrm{~N}_{5} \mathrm{O}_{9}$ $\left[(3+2 \mathrm{H})^{2+}\right]$ 914.8, found $915.6(100 \%)$.

\section{Electrochemical and spectroelectrochemical measurements}

For CV measurements, electrochemical or analytical grade tetrabutylammonium hexafluorophosphate (TBAH) from Sigma-Aldrich was used as received as a supporting electrolyte. Solvent dichloromethane (DCM) from Sigma-Aldrich was purified and dried by refluxing over and successively distilling from $\mathrm{B}_{2} \mathrm{O}_{3}$ and activated $4 \AA$ molecular sieves. Afterward, it was stored in specially designed Schlenk flasks over $3 \AA$ activated molecular sieves, protected from light, and kept under vacuum prior to use, as reported elsewhere. ${ }^{43}$

The solvent was distilled via a closed system into a custom designed electrochemical cell (as described below) containing the supporting electrolyte and the species under examination, immediately before performing the experiment.

Electrochemical experiments were carried out in an airtight single-compartment cell using platinum as working and counter electrodes and a silver spiral as a quasi-reference electrode. The drift of the quasi-reference electrode was negligible during the time required for an experiment. All the $E_{1 / 2}$ potentials have been directly obtained from cyclic voltammetric curves as averages of the cathodic and anodic peak potentials and by digital simulation in the case of not Nernstian or overlapping processes. The $E_{1 / 2}$ values have been determined by adding ferrocene $(\mathrm{Fc})$, at the end of each experiment, as an internal standard and measuring them with respect to the ferrocinium/ ferrocene couple $\left(\mathrm{Fc}^{+/ 0}\right)$ standard potential (at $298 \mathrm{~K}$ it is $+0.42 \mathrm{~V}$ vs. SCE, i.e., the aqueous Saturated Calomel Electrode). ${ }^{44}$

The cell containing the supporting electrolyte and the electroactive compound was dried under vacuum at $100-110{ }^{\circ} \mathrm{C}$ for at least 48 hours before each experiment. The pressure measured in the electrochemical cell prior to perform the trap-to-trap distillation of the solvent was typically $1 \times 10^{-5}$ mbar. Voltammograms were recorded with a custom made fast and low current potentiostat ${ }^{45}$ controlled by an AMEL Mod. 568 programmable function generator. The potentiostat was interfaced to a Nicolet Mod. 3091 digital oscilloscope and the data transferred to a personal computer by the program Antigona. ${ }^{46}$ Minimization of the uncompensated resistance effect in the voltammetric measurements was achieved by the positivefeedback circuit of the potentiostat. Digital simulations of the cyclic voltammetric curves were carried out either by Antigona or 
DigiElch 7, utilizing a best fitting procedure of the experimental curves recorded at different scan rates spanning over, at least, two orders of magnitude.

The spectroelectrochemical experiments have been carried out using a quartz OTTLE cell with a $0.03 \mathrm{~cm}$ path length. Temperature control was achieved by a special cell holder with quartz windows, in which two nitrogen fluxes (one at room temperature and the other at low temperature) were regulated by needle valves. The spectra have been recorded by a Cary 5 (Varian) and all the experimental details for the spectroelectrochemical setup have been reported elsewhere. ${ }^{47}$

\section{Steady-state spectroscopy}

Steady-state absorption and emission measurements were performed on freshly prepared air-equilibrated solutions. Solvents (toluene and chloroform) were spectrophotometric grade and were used as received. Absorption spectra were collected with a PerkinElmer Lambda650 double-beam UV/vis spectrophotometer. Molar extinction coefficients were estimated from the absorbances of four different solutions with known concentration, and the Lambert-Beer law was verified over the investigated concentration range $\left(10^{-5}-10^{-6} \mathrm{M}\right)$.

Fluorescence measurements were performed at room temperature on dilute solutions (optical density $<0.1$ at the excitation wavelength). Fully corrected emission spectra were recorded with a Fluoromax-3 Horiba-Jobin Yvon fluorometer. Fluorescence quantum yields were estimated using a dilute solution of fluorescein in $\mathrm{NaOH} 0.1 \mathrm{M}$ as the standard (QY = $\left.90 \%, \lambda_{\text {exc }}=460 \mathrm{~nm}\right)$.

Singlet oxygen production was assessed under ambient conditions exploiting ${ }^{1} \mathrm{O}_{2}$ phosphorescence in the near-IR. ${ }^{1} \mathrm{O}_{2}$ emission spectra were collected with an Edinburgh FLS1000 spectrofluorometer equipped with a Xe excitation source and near-IR PMT detector in liquid nitrogen cooled housing. Singlet oxygen quantum yields were estimated as detailed in ESI. $\dagger$ Phosphorescence lifetimes were obtained with the multi-channel scaling (MCS) technique, following the decay at $1273 \mathrm{~nm}$ after photoexcitation with a microsecond flashlamp. Lifetimes were extracted by reconvolution fit or tail fit of the experimental decay traces and the goodness of the fit was judged by the chi-squared test.

\section{Transient spectroscopy}

The system used to record transient absorption spectra (TAS) has been previously described. ${ }^{48}$ Briefly, the setup is composed of an integrated Ti:sapphire oscillator-regenerative amplifier system (Spectra Physics Tsunami-BMI Alpha 1000) delivering $100 \mathrm{fs}$ pulses centred at $800 \mathrm{~nm}$. A small portion of the fundamental laser radiation is used to produce the white light probe beam, obtained by focusing the $800 \mathrm{~nm}$ light on a $3 \mathrm{~mm}$ thick $\mathrm{CF}_{2}$ window, kept under continuous rotation to avoid damage. The generated white light is then divided into a probe and reference beam through a $50 \%$ beamsplitter. The visible pump pulse has been set at $530 \mathrm{~nm}$ for excitation of 3 and 4 while at $400 \mathrm{~nm}$ for exciting $\mathbf{5}$. The $530 \mathrm{~nm}$ excitation beam was generated by pumping a home-made non collinear optical parametric amplifier (NOPA) with a portion of the fundamental $800 \mathrm{~nm}$ light. Excitation light at $400 \mathrm{~nm}$ was obtained through second harmonic generation of the fundamental laser output using a $1 \mathrm{~mm}$ thick BBO crystal. Excitation powers were about 50-100 nJ. The pump beam polarization has been set to magic angle with respect to the probe beam by rotating a $\lambda / 2$ plate, to exclude rotational contributions. Before the generation of the probe light, the portion of fundamental radiation directed on the probe/reference pathway was sent through a motorized delay stage, which allows to vary the relative time of arrival of pump and probe beams and to collect transient spectra in a temporal interval going up to $1.5 \mathrm{~ns}$. Both pump and probe were overlapped at the sample position through a $150 \mathrm{~mm}$ spherical mirror. After passing through the sample, the white light probe and reference pulses were both directed to a flat field monochromator coupled to a home-made CCD detector. The sample was contained in a $2 \mathrm{~mm}$ quartz cuvette, mounted on a motorized stage in order to minimize photodegradation. Transient data have been analysed using a global analysis procedure, which consists of the simultaneous fit at all the acquired frequencies with sums or combination of exponential decay functions. ${ }^{49}$ Global analysis was performed using the GLOTARAN package (http://glotaran.org), employing a linear unidirectional "sequential" model. ${ }^{50,51}$ The number of kinetic components to be used in the global fit is determined by a preliminary singular values decomposition (SVD) analysis performed with the same software. ${ }^{52}$

\section{Computational details}

A preliminary conformational search for dyad $\mathbf{3}$ was performed in vacuum with molecular mechanics. In order to restrict the number of possible structures, as suggested by a previous work, ${ }^{32}$ we performed a scan along each dihedral angle of the two spacers and, for each point of the scan, we optimized the geometry with MMFF94 force field ${ }^{53-57}$ (PCmodel software, v. 10.0). ${ }^{58}$ Among the structures characterized by an open conformation of the calixarene macrocycle (suggested by NMR data), the most stable were then reoptimized with MMFF94 and were used as starting point for DFT calculations. DFT optimizations were performed in gas phase with Gaussian16 package, ${ }^{59}$ adopting the long-range-corrected hybrid $\omega$ B97XD functional ${ }^{60}$ and $6-31 \mathrm{G}$ basis set. Stationary points were characterized by frequency analysis. The geometry of the most stable conformer (open) was reoptimized in solution (toluene), treating the solvent according to the polarizable continuum model (PCM) formalism. ${ }^{61}$

\section{Results and discussion}

\section{Synthesis}

The synthesis of Nile Red- $\mathrm{C}_{60}$ calix[4]arene 3 is reported in Scheme 1.

The dicarboxylic acid tetrapropoxycalix[4] arene $\mathbf{1}^{\mathbf{4 2}}$ was first activated as acyl chloride and immediately reacted with an equimolar mixture of $\mathbf{N R - \mathbf { N H } _ { 2 }}$ and 2,2-diethoxyethanamine. 

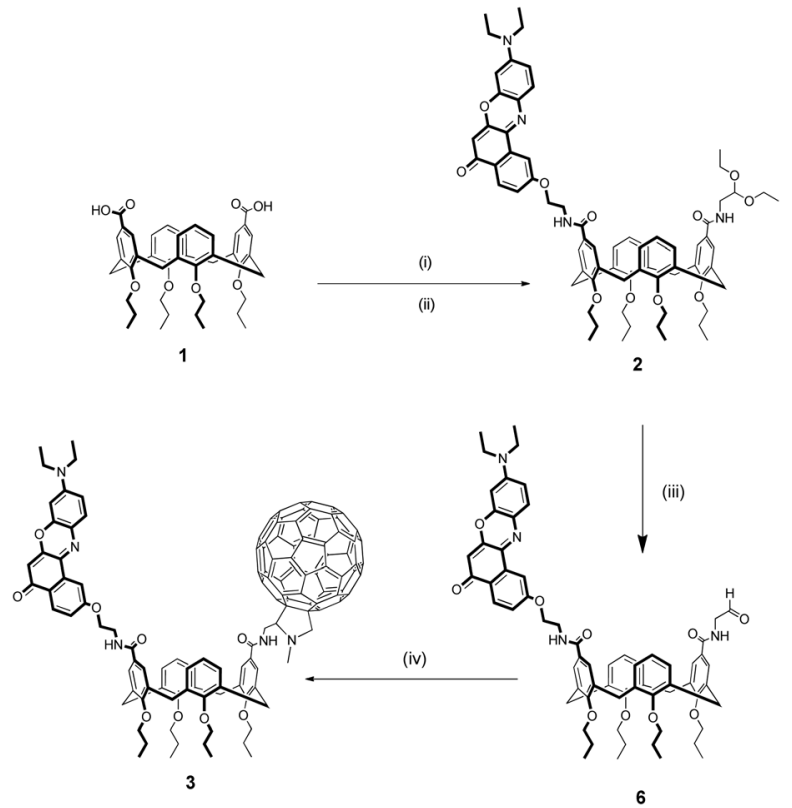

Scheme 1 Synthesis of Nile Red- $\mathrm{C}_{60}$ calix[4]arene 3: (i) $(\mathrm{COCl})_{2}, \mathrm{DMF}$, DCM, 5 h, r.t., quantitative; (ii) 2,2-diethoxyethanamine, NR-NH $\mathbf{N}_{2}$ DIPEA, $\mathrm{DCM}, 12$ h, r.t., $47 \%$; (iii) $\mathrm{HCl}(1 \mathrm{M})$, dioxane, 4 h, r.t., $77 \%$; (iv) $\mathrm{C}_{60}$, sarcosine, toluene, reflux, $3 \mathrm{~h}, 23 \%$.

This mixed-condensation strategy allowed to obtain the heterodifunctionalized calixarene $\mathbf{2}$ in a single step after chromatography separation from the homodifunctionalized byproducts. After removal of the acetal protecting group, the resulting aldeyhde was subjected to the Prato reaction ${ }^{62}$ with $\mathrm{C}_{60}$ and sarcosine in toluene to afford product 3 as a dark purple solid in $23 \%$ yield.

Reference monochromophoric compound 5 was synthesized with a similar strategy starting from monocarboxylic acid tetrapropoxycalix[4]arene (see ESI $\dagger$ ).

\section{Conformational properties}

$\mathrm{C}_{60}$-Nile Red calixarene 3 was characterized in $\mathrm{CDCl}_{3}$ solution by NMR. 2D COSY and ROESY spectra (Fig. S2 and S3, ESI $\dagger$ ) were required to fully assign all the ${ }^{1} \mathrm{H}$ NMR signals, due to the asymmetric nature of the molecule. Importantly, besides confirming the identity of the compound, ${ }^{1} \mathrm{H}$ NMR spectroscopy allowed to investigate the conformational properties of the calixarene scaffold.

In general, the most stable conformation of a calix[4]arene in the cone geometry tetra-alkylated at the lower rim is the so-called pinched cone structure (Fig. 2a), where two opposite
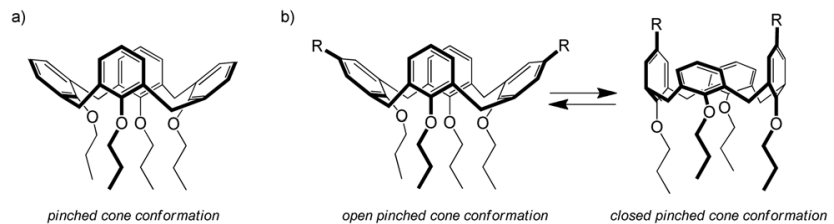

Fig. 2 (a) Pinched cone conformation of a calix[4]arene; (b) equilibrium between the open and closed conformations of a cone calix[4]arene with two substituents on the distal positions of the upper rim. aromatic rings point slightly inwards and the other two are tilted outwards. ${ }^{33}$ Calix[4] arenes with identical substituents on the four rings rapidly interconvert between the two opposite pinched cone structures and their ${ }^{1} \mathrm{H}$ NMR spectrum, which reflects the time-averaged conformation, is indicative of a regular cone structure. On the contrary, for calixarenes like 3, with two substituents on the distal positions of the upper rim, the stabilities of the two conformations are no longer equal, depending on the interactions between the substituents (attractive or repulsive). In cases like this, ${ }^{1} \mathrm{H}$ NMR spectroscopy allows to distinguish if the preferred conformation is the open (with the functionalized rings pointing outwards) or the closed (functionalized rings pointing inwards) pinched cone (Fig. 2b) from the relative position of the signals of the aromatic protons: the two rings pointing inwards experience the magnetic shielding cone of the other two rings and their resonances are shifted to higher fields.

For compound 3, the aromatic signals (singlets at 7.17, 7.05 and $6.98 \mathrm{ppm}$ for the protons ortho to the amide group, which resonate at lower fields than the multiplet between 6.57$6.49 \mathrm{ppm}$ and the triplet at $6.53 \mathrm{ppm}$ of the protons on the unsubstituted aromatic rings) suggest an open conformation for the calixarene scaffold. This finding was not obvious, according to our experience. In previous works some of us have studied calix[4]arenes similar to 3 , functionalized at the upper rim with pairs of different chromophores linked to the calixarene through an analogous amide linkage. ${ }^{28,32}$ These compounds were found to adopt a closed structure thanks to the formation of an intramolecular hydrogen bond between the $\mathrm{NH}$ and $\mathrm{CO}$ groups of the amide moieties. In case of compound 3 , most likely the steric hindrance of the fullerene prevents the formation of the intramolecular CO $\cdots \mathrm{HN}$ hydrogen bond. Even in presence of a prevalent open conformation of the macrocycle, however, the flexibility of the linkers should guarantee the possibility for the dyes to get in close contact.

The conformational properties of the dyad were also investigated computationally. The four structures reported in Fig. S4 (ESI $\dagger$ ) were singled out from conformational analysis in gas phase: the open conformer, where the two chromophores point in two different directions out of the calixarene; the open_NR and open_C60 conformers, where the Nile Red and the $\mathrm{C}_{60}$ moiety, respectively, point toward the center of the calixarene; the open_NR_C60 conformer, where both Nile Red and $\mathrm{C}_{60}$ point toward the center of the calixarene. Total ground state free energies of the conformers are summarized in Table S1 (ESI $\dagger$ ). The open conformation is the most stable, the open_NR is only slightly more energetic, the open_NR_C60 and open_C60 have significantly higher energies but are still accessible at room temperature. The interchromophoric distance, taken as the distance between the centroids of Nile Red and $\mathrm{C}_{60}$, is also reported in Table $\mathrm{S} 1$ (ESI $\dagger$ ), ranging from 8 to $14 \AA$ according to the conformer. The geometry of the most stable conformer was also optimized in toluene, giving a very similar structure as in gas phase (compare the interchromophoric distance in Table S1, ESI $\dagger$ ). We underline that the discussed conformers are just four out of a plethora of possible 
conformations allowed by the flexibility of the linkers: the data on these selected conformers should just be used to have an idea of the mean distance between the two donor/ acceptor moieties and about the frontier orbitals (reported in Fig. S5-S9, ESI $\dagger$ ).

\section{Steady-state spectroscopic characterization}

Dyad 3 and reference compounds $\mathbf{4}$ and $\mathbf{5}$ were characterized by steady-state spectroscopy in toluene and chloroform airequilibrated solutions. Absorption and emission spectra are shown in Fig. 3, while main spectroscopic properties are listed in Table 1.

Spectra of 4 feature the characteristic absorption band of Nile Red between 450 and $600 \mathrm{~nm}$, and an intense emission signal peaking at $\lambda>550 \mathrm{~nm}$. Fluorescence quantum yields are high $(\approx 80 \%)$ in both the solvents, with a radiative rate constant amounting to $1.7 \times 10^{8} \mathrm{~s}^{-1}$ quite independently of the solvent. $^{32}$ Absorption and emission bands of $\mathbf{4}$ retain the positive solvatochromism of Nile Red, suggesting that the presence of the calixarene scaffold does not perturb the electronic properties of the chromophore. ${ }^{63}$
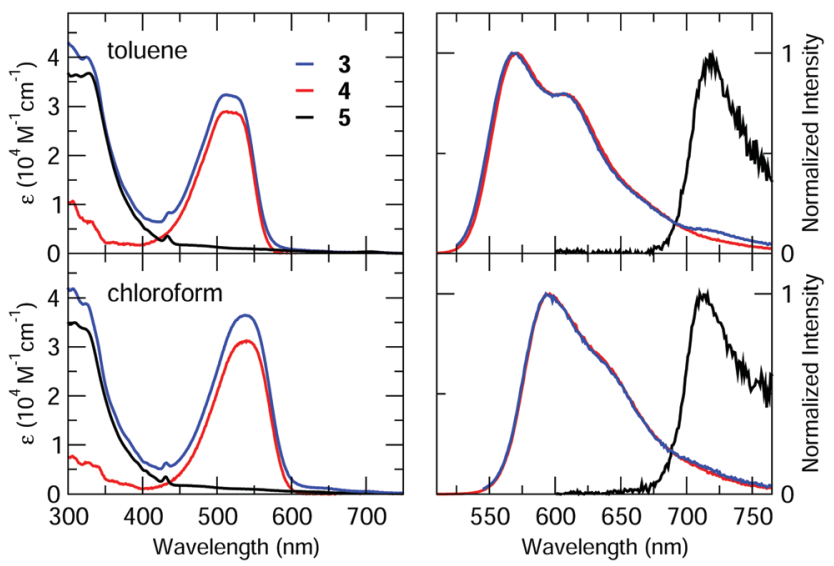

Fig. 3 Steady-state absorption (left) and normalized emission (right) spectra of the investigated compounds in toluene (top panels) and chloroform (bottom panels). Emission spectra of $\mathbf{3}$ were collected for excitation at $\lambda=515 \mathrm{~nm}$ in toluene and $\lambda=540 \mathrm{~nm}$ in chloroform.

Table 1 Spectroscopic data of 3, 4 and 5 in toluene and chloroform: absorption and emission maxima ( $\lambda_{\mathrm{abs}}^{\max }$ and $\lambda_{\mathrm{em}}^{\max }$ ), molar extinction coefficient at $\lambda_{\mathrm{abs}}^{\max }\left(\varepsilon_{\max }\right)$ and fluorescence quantum yield (QY). Fluorescence quantum yields were estimated using fluorescein in $\mathrm{NaOH}(\mathrm{aq}) 0.1 \mathrm{M}$ as the standard (QY = 90\%)

\begin{tabular}{lrrlll}
\hline & & $\lambda_{\mathrm{abs}}^{\max } / \mathrm{nm}$ & $\varepsilon_{\mathrm{max}} / \mathrm{M}^{-1} \mathrm{~cm}^{-1}$ & $\lambda_{\mathrm{em}}^{\max } / \mathrm{nm}$ & $\mathrm{QY} / \%\left[\lambda_{\mathrm{exc}} / \mathrm{nm}\right]$ \\
\hline Toluene & $\mathbf{3}$ & 514 & 32000 & 567 & $1.9[515]$ \\
& $\mathbf{4}$ & 513 & 29000 & 570 & $84[530]$ \\
& $\mathbf{5}$ & $<350$ & $>30000$ & 718 & $-{ }^{b}$ \\
Chloroform & $\mathbf{3}$ & 538 & 36000 & 593 & $2.7[540]$ \\
& $\mathbf{4}$ & 540 & 31000 & 596 & $78^{a}$ \\
& $\mathbf{5}$ & $<350$ & $>30000$ & 710 & $-^{b}$
\end{tabular}

${ }^{a}$ Data from ref. $32 .{ }^{b}$ Not determined.
Similarly, compound $\mathbf{5}$ displays the main spectroscopic properties of $\mathrm{C}_{60}$. Indeed, its absorption spectrum covers most of the UV/visible range, with small molar extinction coefficient in the 400-750 $\mathrm{nm}$ spectral window $\left(\varepsilon<10^{3} \mathrm{M}^{-1} \mathrm{~cm}^{-1}\right)$ and intense bands $\left(\varepsilon>10^{4} \mathrm{M}^{-1} \mathrm{~cm}^{-1}\right)$ at shorter wavelengths. ${ }^{64}$ The peak at $\lambda \approx 430 \mathrm{~nm}$ is instead related to $\mathrm{C}_{60}$ substitution, and is usually found in fulleropyrrolidine derivatives. ${ }^{23,65-67}$ The weak fluorescence of $\mathbf{5}$, which is independent of solvent polarity and excitation wavelength, was found beyond $700 \mathrm{~nm}$ as typical of $\mathrm{C}_{60} \cdot{ }^{68}$

Absorption spectra of the dyad 3 are roughly the sum of the corresponding spectra of $\mathbf{4}$ and 5, ruling out the occurrence of strong interchromophoric interactions in the ground state. Emission spectra of 3 can also be qualitatively viewed as the sum of the contributions from the two chromophoric units, however, because of the sizeable difference between the fluorescence efficiencies of the two dyes, emission of 3 is dominated by the Nile Red contribution, while fluorescence of $\mathrm{C}_{60}$ can be recognized only in the long-wavelength tail of the spectrum. Nevertheless, fluorescence of Nile Red is strongly quenched in 3, being approximately 40 and 30 times less intense than in 4 in toluene and chloroform, respectively (see Table 1). This strong quenching suggests the activation of new efficient decay channels (energy and/or charge transfer towards $\mathrm{C}_{60}$ ).

Distinguishing energy and charge transfer processes through the analysis of steady-state absorption and emission spectra is not an easy task, most of all when donor and acceptor moieties are characterized by very different emission quantum yields, as in this case. In fact, the emission spectrum of 3 is dominated by the fluorescence of Nile Red despite the strong quenching that it undergoes, so that deconvolving the emission of the $\mathrm{C}_{60}$ moiety with a good confidence is not possible. We then decided to investigate the fate of the excited state of Nile Red in the dyad via the evaluation of the ability of 3 to produce singlet oxygen.

Fullerenes are good singlet molecular oxygen sensitizers. ${ }^{69,70}$ Indeed, photoexcitation of 5 in the UV $(370 \mathrm{~nm})$ leads to the appearance of the characteristic ${ }^{1} \mathrm{O}_{2}$ photoluminescence at $1273 \mathrm{~nm}$ in both the analysed solvents. Values estimated in chloroform amount to $\approx 50 \%$ with respect to those retrieved in toluene (Table S3, ESI $\dagger$ ). Singlet oxygen production was detected also for dyad 3 for excitation within the Nile Red absorption band (Fig. S10, ESI $\dagger$ ), while was not found in reference compound 4 under the same experimental conditions (Fig. S11, $\mathrm{ESI} \dagger$ ). The comparison between the ${ }^{1} \mathrm{O}_{2}$ emission intensities for 3 and 5 allowed for the estimate of their relative singlet oxygen quantum yield (see ESI $\dagger$ ). Noticeably, in both solvents, the singlet oxygen quantum yield of the dyad 3 , obtained for (almost) selective excitation of Nile Red $\left(\lambda_{\mathrm{exc}}=530\right.$ and $540 \mathrm{~nm}$ in toluene and chloroform, respectively) is not reduced, within the experimental error, compared to reference compound $\mathbf{5}$. This suggests that, in the dyad, the singlet excited state localized on Nile Red quantitatively converts into an excitation localized on $\mathrm{C}_{60}$.

The quantitative conversion of excitation energy from Nile Red to $\mathrm{C}_{60}$ in 3 deserves more investigation. In fact, the 
formation of the $\mathrm{C}_{60}$ triplet (responsible for the formation of singlet oxygen) can be due to different mechanisms, namely: (i) FRET from Nile Red to $\mathrm{C}_{60}$, creating the singlet excited state of $\mathrm{C}_{60}$, followed by intersystem crossing (ISC) to form the $\mathrm{C}_{60}$ triplet; (ii) electron transfer from the singlet excited state of Nile Red towards an empty $\mathrm{MO}$ of $\mathrm{C}_{60}$, creating a biradical chargeseparated state, followed by triplet formation by charge recombination. ${ }^{2,4}$

\section{Electrochemical and spectroelectrochemical characterization}

The redox behaviour of the compounds has been investigated by cyclic voltammetry in highly dry dichloromethane (DCM) solution.

The voltammetric curves of the dyad 3 and those of the different constituent moieties, namely compound $\mathbf{5}$, a reference $\mathbf{C}_{60}-\mathbf{P h}$ compound (see ESI $\dagger$ ), and compound $\mathbf{4}$, are reported in Fig. 4. For all the compounds, the redox processes studied at room temperature occur within the potential window comprised between about $+1.2 \mathrm{~V}$ and $-2.3 \mathrm{~V}$, with a particular rich voltammetric pattern in the negative potentials region for the species containing fullerene. The $E_{1 / 2}$ potentials of the various processes are collected in Table 2 .

Dyad 3 (Fig. 4a) shows globally an oxidation process at positive potentials and four voltammetric waves at negative potential values. The oxidation is a completely irreversible process at a scan rate of $1 \mathrm{~V} \mathrm{~s}^{-1}$ and the voltammetric peak morphology indicates a sluggish electron transfer. Moreover, a repetitive potential scan evidences a progressive passivation of the electrode surface, due to some product of the irreversibility.

Examination of Fig. $4 \mathrm{a}$ and $\mathrm{c}$ shows that the oxidation of the dyad can be easily attributed to the Nile Red moiety, as the first oxidation of fullerene is at $1.69 \mathrm{~V}(v s \text {. SCE })^{71}$ and the calixarene does not show any redox process neither at the positive nor at the negative potential range explored in this work.

Concerning the reductions of $\mathbf{3}$, the first peak at negative potentials, centred at about $-0.75 \mathrm{~V}$, is completely reversible and can be attributed to the $\mathrm{C}_{60}$ unit. This is supported by comparing the first reduction of the cyclic voltammetric curves of 3 (Fig. 4a) and those of $\mathbf{5}$ and $\mathbf{C}_{60}-\mathbf{P h}$ (Fig. $4 \mathrm{~b}$, blue and red lines, respectively), that occur at the same potential.

The second reduction voltammetric wave of dyad 3 is reversible and is due to two closely spaced reduction processes: one attributed to the $\mathrm{C}_{60}$ and the other to the Nile Red moiety, as it can be easily inferred by comparing the corresponding potential values in Table 2 and the voltammetric curves in Fig. $4 \mathrm{~b}$ and $4 \mathrm{c}$. It is worth noticing that, despite the cathodic peak potential of the sluggish reduction process of the Nile Red species (see Fig. 4c) is at $-1.30 \mathrm{~V}$, it does not give rise to any shoulder at the more negative potential side of the second voltammetric wave. In fact, the $\mathrm{E}_{1 / 2}$ potential of the Nile Red reduction is at $-1.10 \mathrm{~V}$, that is very close to the second reduction potential of $\mathrm{C}_{60}$ and thus a catalytic reduction of the Nile Red moiety by the more reversible $\mathrm{C}_{60}{ }^{2-}$ is observed. This suggests some kind of intramolecular interaction between the units $\mathrm{C}_{60}$ and Nile Red in the dyad.
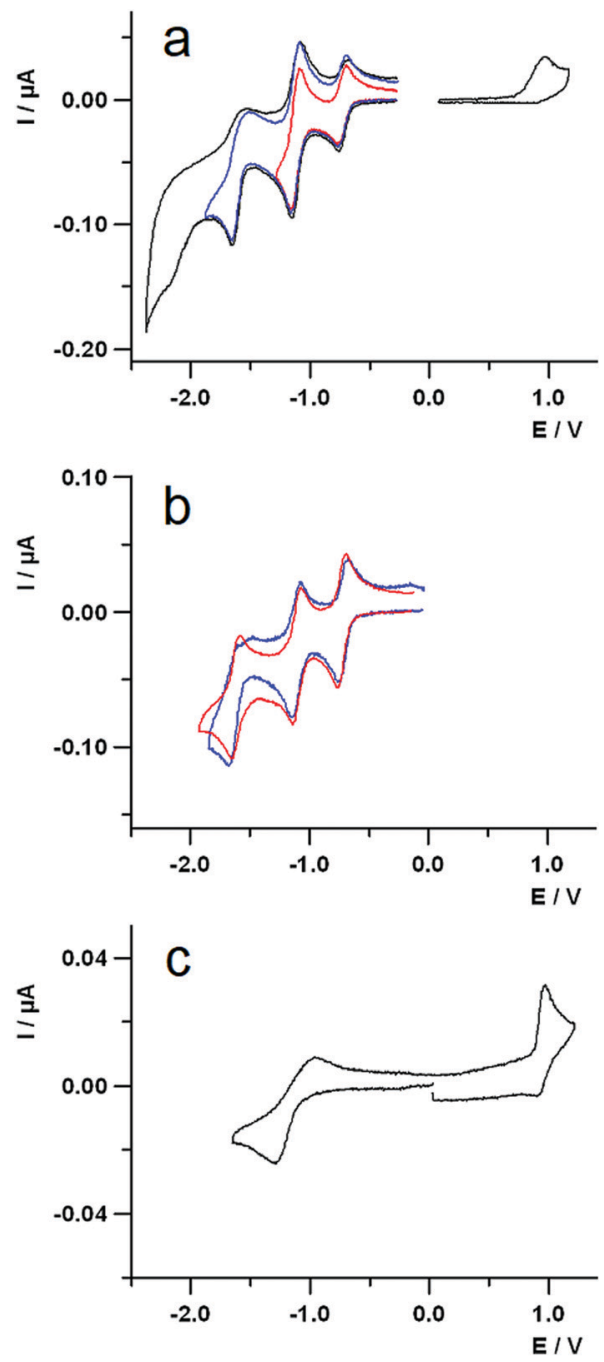

Fig. 4 Cyclic voltammetric curves of (a) $0.6 \mathrm{mM}$ species 3 (three scans at different inversion potential); (b) $0.7 \mathrm{mM}$ compound $\mathbf{C}_{60}-\mathbf{P h}$ (blue line) and 5 (red line); (c) $0.7 \mathrm{mM}$ species 4 recorded in TBAH/DCM at $298 \mathrm{~K}$. Scan rate $=1 \mathrm{~V} \mathrm{~s}^{-1}$; working electrode: platinum disk (diameter $125 \mu \mathrm{m}$ ); reference electrode: SCE.

Table 2 Half-Wave $\left(E_{1 / 2}\right)$ redox potentials (vs. SCE) of compounds recorded in TBAH/DCM solution at $25^{\circ} \mathrm{C}$

\begin{tabular}{llllll}
\hline & & \multicolumn{4}{l}{$E_{1 / 2} / \mathrm{V}-$ (reduction) } \\
\cline { 3 - 6 } Species & $E_{1 / 2} / \mathrm{V}$ (oxidation) & $\mathrm{I}$ & $\mathrm{II}$ & $\mathrm{III}$ & $\mathrm{IV}$ \\
\hline $\mathbf{3}$ & $0.96^{a c}$ & -0.73 & $-1.09^{b}$ & -1.62 & $-2.15^{a b}$ \\
& & & $-1.14^{b}$ & & \\
$\mathbf{5}$ & - & -0.72 & -1.11 & $-1.68^{a c}$ & - \\
$\mathbf{C}_{\mathbf{6 0}}-\mathbf{P h}$ & - & -0.73 & -1.11 & -1.62 & - \\
$\mathbf{4}$ & $0.93^{b}(0.97)^{a c}$ & -1.10 & - & - & -
\end{tabular}

${ }^{a}$ Irreversible process. ${ }^{b} E_{1 / 2}$ potential determined by digital simulation of the voltammetric curve. ${ }^{c}$ Peak potential.

The third reduction peak of 3 (Fig. 4a) is attributed to the third reduction of fullerene, on the basis of similar arguments as above. The fourth irreversible peak is also centred on the $\mathrm{C}_{60}$, as reported in literature. ${ }^{71}$ 
The redox results are in agreement with the scenario given by the calculated frontier molecular orbitals, for all the four selected conformers (Fig. S5-S9, ESI $\dagger$ ).

The UV-Vis-NIR spectroelectrochemical study of the dyad has been performed to ascertain both the attribution of the first redox processes as well as to gain further insights on the photoinduced processes. Fig. 5a shows the spectra of the pristine compound (black line), that of the one-electron reduced species (red line) and all those representing the spectral evolution from the initial to the final reduced species (thin black lines). The difference spectrum, representing the change upon reduction, is reported in Fig. 5b, showing a sharp negative band at about $270 \mathrm{~nm}$, due to the injection of the first
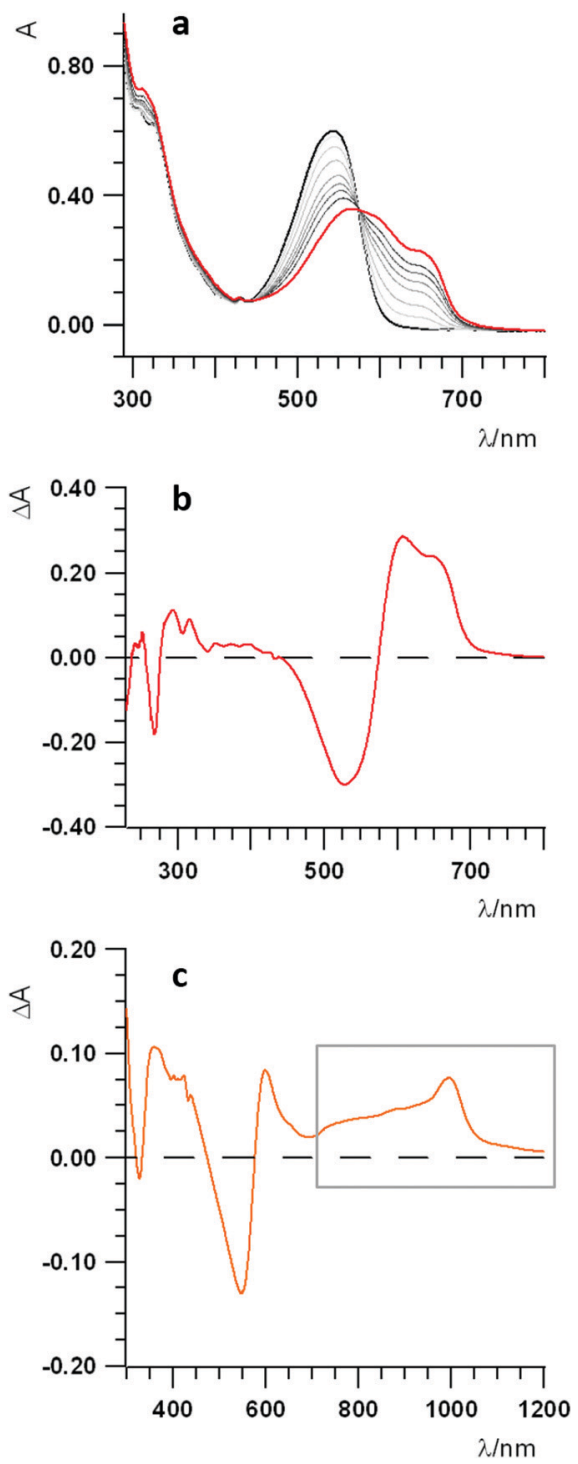

Fig. 5 (a) UV-Vis-NIR spectra of $0.6 \mathrm{mM}$ dyad 3 in $0.08 \mathrm{M}$ TBAH/DCM solution; working electrode, Pt gauze; temperature $=0{ }^{\circ} \mathrm{C}$. Spectra of the pristine compound (black line) and one-electron reduced species (red line). (b) Difference spectrum of the reduced state (red trace; spectrum of the pristine compound subtracted). (c) UV-Vis-NIR difference spectrum of the oxidized state of dyad $30.6 \mathrm{mM}$ in $0.08 \mathrm{M} \mathrm{TBAH/DCM}$ solution; working electrode, Pt gauze; temperature $=0{ }^{\circ} \mathrm{C}$. electron into the fullerene, ${ }^{72}$ another negative, larger band at about $540 \mathrm{~nm}$, and a positive band forming at longer wavelengths. The peak at about $540 \mathrm{~nm}$ is a transition occurring on the Nile Red moiety that, unexpectedly, is involved by the first reduction centred on $\mathrm{C}_{60}$. This suggests that some interaction exists in dyad 3 between the one-electron reduced fullerene and Nile Red, thus perturbing the electronic transitions of the Nile Red itself. $^{73}$

A spectroelectrochemical investigation about the oxidation of 3 has been tentatively performed with less clear evidences, due to the chemically irreversible electron transfer, as discussed in the electrochemical characterization. The difference spectrum for the oxidation is plotted in Fig. 5c, showing a bleaching of the band at about $540 \mathrm{~nm}$ and the increase of some bands both in the $380-450 \mathrm{~nm}$ spectral range and on the red side of the spectrum, from about $600 \mathrm{~nm}$ up to the near IR region (highlighted by a grey box in Fig. 5c), with a peak at about $1000 \mathrm{~nm}$.

\section{Transient spectroscopy}

To better investigate the mechanism and dynamics of energy/ charge transfer upon excitation of Nile Red in dyad 3, we performed transient absorption experiments with sub-picosecond time resolution, comparing the results for the dyad with those for the single-chromophore reference compounds $\mathbf{4}$ and $\mathbf{5}$.

In particular, compounds 3 and 4 were excited at $530 \mathrm{~nm}$, and compound 5 was excited at $400 \mathrm{~nm}$, and the excited state dynamics was recorded in the visible spectral region $(400-750 \mathrm{~nm})$. Measurements were performed both in toluene and chloroform.

Fig. 6a reports the experimental transient spectra of dyad 3 dissolved in toluene (the transient spectra and EADS of all compounds measured in chloroform are reported in ESI, $\dagger$ Fig. S12). The negative bands centered around $540 \mathrm{~nm}$ and $615 \mathrm{~nm}$ are respectively associated with ground state bleaching (GSB) and stimulated emission (SE), while the positive bands around 470 and $545 \mathrm{~nm}$ are excited state absorption (ESA) of the Nile Red unit. Indeed, all these spectral features are also visible in the transient spectra of compound 4 (Fig. 6b). In both solvents, the GSB and SE signals of dyad 3 recover on a faster timescale as compared to the isolated compound $\mathbf{4}$. Furthermore, on a longer timescale, the SE signal of dyad 3 is replaced by a positive broad signal peaking at about 680$700 \mathrm{~nm}$. The latter band is also recognized in the transient spectra of the reference compound 5 (Fig. 6c), allowing to assign this feature to the $\mathrm{C}_{60}$ unit.

For compound 5 (Fig. 6c), the GSB is not observed in the probed spectral region, because the most intense absorption of compound $\mathbf{5}$ is located at shorter wavelengths (the excitation wavelength in this case is at $400 \mathrm{~nm}$ ). In the visible region, the absorption of compound $\mathbf{5}$ has a very low intensity, so that the GSB is compensated by a broad ESA band, which covers all the probed spectral range. This broad ESA appears immediately after excitation, and does not show significant spectral changes within the first nanosecond. On a timescale of about $1 \mathrm{~ns}$, we observe the rise of a positive signal peaked at around $700 \mathrm{~nm}$, that has been ascribed in the literature to the absorption of the fullerene triplet. ${ }^{74}$ 
a

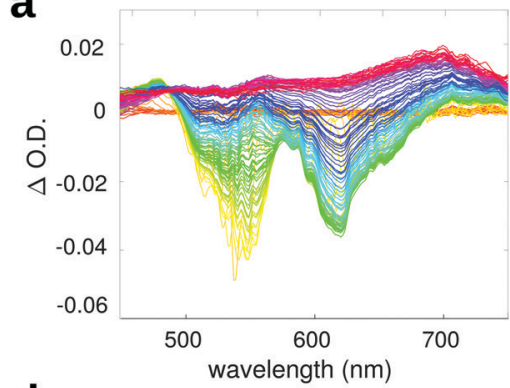

d

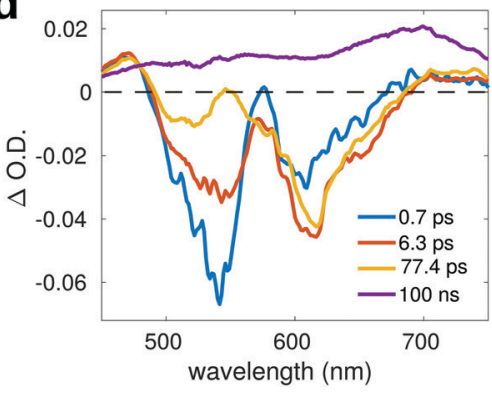

b

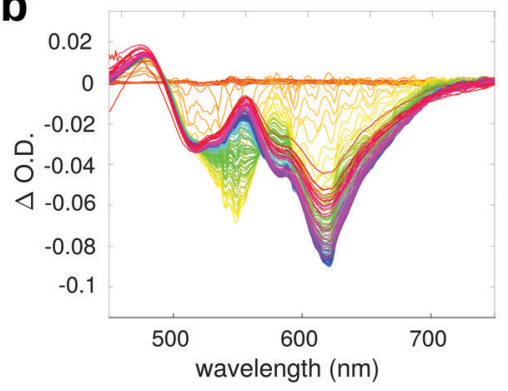

e

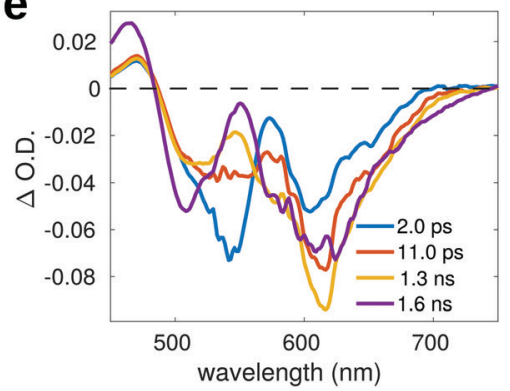

C

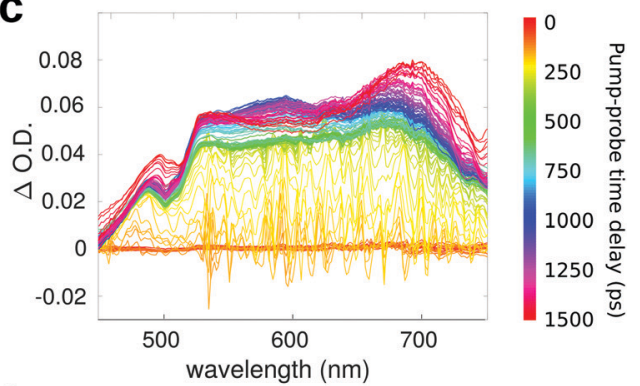

f

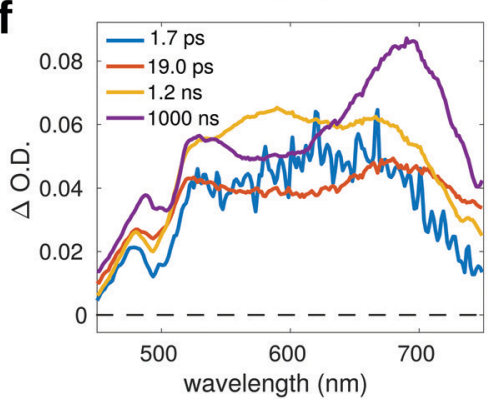

Fig. 6 Transient spectra of: (a) compound $3\left(\lambda_{\mathrm{exc}}=530 \mathrm{~nm}\right)$, (b) compound $\mathbf{4}\left(\lambda_{\mathrm{exc}}=530 \mathrm{~nm}\right)$ and (c) compound $5\left(\lambda_{\mathrm{exc}}=400 \mathrm{~nm}\right)$ in toluene. Panels $(d-f)$ report the respective EADS obtained from global analysis.

Global analysis has been performed to extract the kinetic constants associated to the excited state relaxation of dyad 3 and of the reference compounds in the two solvents. The Evolution Associated Difference Spectra (EADS) are obtained under the assumption that the excited state population evolves following a sequential kinetic scheme described by a multiexponential trend: each EADS represents the spectral component associated with a decay time constant. In our case, the results of global analysis show that the excited state dynamics can be well described using four time constants in all the studied samples.

For dyad 3 in toluene (Fig. 6d), the initial EADS (blue line) forms almost instantaneously after excitation and decays with a lifetime of 0.7 ps. This timescale can be associated to a fast relaxation of the excited state. In the second EADS (orange line), it is possible to observe a partial decay of the GSB band at $540 \mathrm{~nm}$ and the increase of the negative SE signal at $615 \mathrm{~nm}$, due to increased emission from a relaxed excited state. The second EADS evolves into the third spectral component (yellow line) with a time constant of $(6.3 \mathrm{ps})^{-1}$ : on this timescale, the negative bleaching signal $(540 \mathrm{~nm})$ keeps decaying and a small ESA signal grows at around $550 \mathrm{~nm}$. The final spectral evolution, occurring on a timescale of $77.4 \mathrm{ps,} \mathrm{is}$ associated to the formation of the fullerene triplet. The final very long lifetime has been arbitrarily fixed at $100 \mathrm{~ns}$, which has to be considered only as an indicative value. The lifetime of the triplet state, which is probably longer than $100 \mathrm{~ns}$, is well beyond the time window probed by our measurement, which allows to record transient spectra with a maximum pumpprobe delay of $1.5 \mathrm{~ns}$. The spectral shape of the final EADS of dyad 3 is very well comparable to the long-living EADS retrieved for compound 5. A similar excited state evolution can be observed in case of chloroform (Fig. S12, ESI $\dagger$ ), with slightly different kinetic constants.
Fig. 6e reports the EADS obtained by global analysis for compound 4 in toluene. Although the spectral shape of the transient signal is very similar to that observed for dyad 3 (with the exclusion of the long-living spectral component), the dynamic evolution of $\mathbf{4}$ is quite different: both GSB and SE bands do not recover on the investigated timescale, indicating that the excited state lifetime of 4 is $>1.5 \mathrm{~ns}$, in agreement with the high fluorescence quantum yield measured for this compound. $^{32}$

To better highlight the contribution of the isolated moieties to the spectra of dyad 3, and to evidence the occurrence of energy/charge transfer processes, in Fig. 7 we compare the transient spectra of compounds 3 and $\mathbf{4}$ at selected pumpprobe delay times.

The spectrum measured on a short delay (1 ps, Fig. 7a) for dyad $\mathbf{3}$ is almost superimposed to that of compound $\mathbf{4}$ upon normalization of their respective intensities. However, the comparison of the transient spectra of compounds $\mathbf{3}$ and $\mathbf{4}$ registered at a pump-probe delay of $10 \mathrm{ps}$ evidences slight differences in the respective spectral shapes. Normalizing the spectra on the intensity of the SE band, an overall increase of the positive signals is observed for dyad 3 as compared to compound 4 , both at the blue side of the probed spectral region $(400-450 \mathrm{~nm})$ and on the red side $(650-750 \mathrm{~nm})$. The small overall positive intensity of the spectrum of dyad 3 as compared to compound 4 could indicate a contribution of the $\mathrm{C}_{60}$ moiety, whose transient spectrum is characterized by a broad positive band extending over the full investigated spectral window on the short timescale, suggesting the occurrence of fast energy transfer. The excited state evolution of compound $\mathbf{3}$ and $\mathbf{4}$ is markedly different on a longer timescale, as evidenced by comparing the kinetic traces recorded on the maximum of the SE band (615 nm) (Fig. S15, ESI $\dagger$ ), showing that the band 

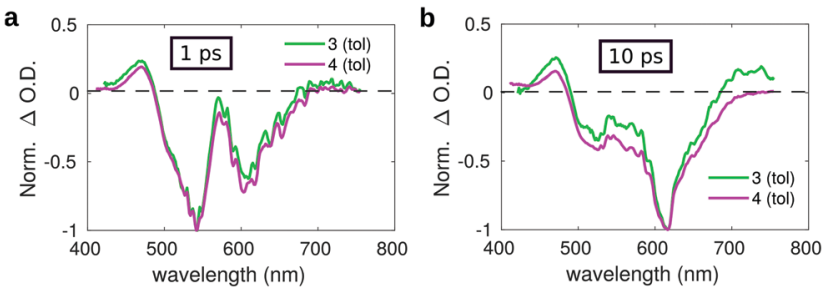

Fig. 7 Comparison between the transient spectra of compound $\mathbf{3}$ (green lines) and $\mathbf{4}$ (violet lines) in toluene registered at a pump-probe delay of: (a) $1 \mathrm{ps}$ and (b) $10 \mathrm{ps}$.

recovery of dyad 3 is much faster as compared to compound 4 . This suggests the occurrence of efficient energy/charge transfer in the dyad.

As previously mentioned, starting from a timescale of about 100 ps up to the maximum pump-probe delay probed with our measurements, the transient spectra of dyad $\mathbf{3}$ are dominated by a positive band which closely reminds that observed in the isolated fullerene. Indeed the comparison of the long-living EADS of compounds $\mathbf{3}$ and $\mathbf{5}$ (Fig. 8a), shows that the transient spectra of the two compounds are almost superimposable and characterized by the presence of the intense ESA band peaked at about $700 \mathrm{~nm}$, which has been previously ascribed to the $\mathrm{C}_{60}$ triplet. $^{74}$

This observation confirms that, in the dyad, the initially formed singlet localized on Nile Red efficiently converts into the triplet excited state of fullerene. The comparison between the single-wavelength kinetic traces recorded at the maximum of the positive band associated to the fullerene triplet (Fig. 8b, other single-wavelength kinetic traces are shown and discussed in ESI $\dagger$ ), indicates that the growth of this peak is highly accelerated in dyad 3 (about 80 ps in toluene and 220 ps in chloroform) with respect to the reference compound 5 ( $\sim 1 \mathrm{~ns}$ ). This result implies that the main formation of the fullerene triplet in dyad 3 does not step through FRET followed by ISC, since in that case the kinetics would not be accelerated with respect to 5. Indeed, previous literature shows that when Förster-type energy transfer between a donor and fullerene
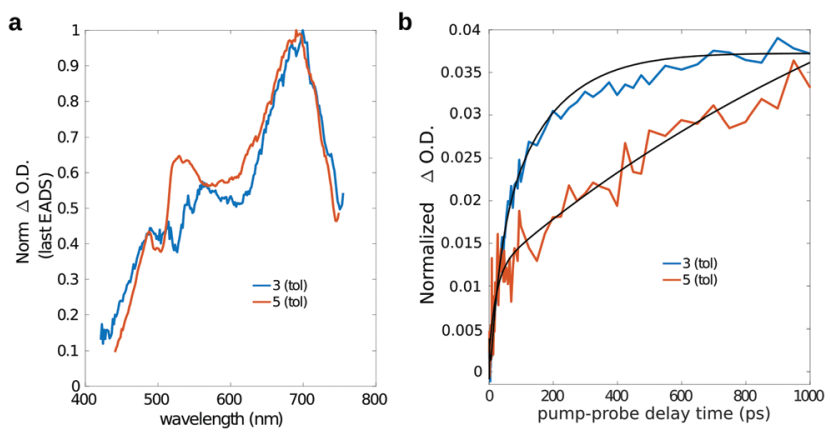

Fig. 8 (a) Long-lived EADS and (b) single-wavelength kinetics at $680 \mathrm{~nm}$ for compound $\mathbf{3}$ (blue lines) and $\mathbf{5}$ (orange lines) in toluene. For a better comparison, a constant offset has been added/subtracted from the time traces of both compound $\mathbf{3}$ and $\mathbf{5}$ to shift their intensity to zero at zero pump-probe delay time.

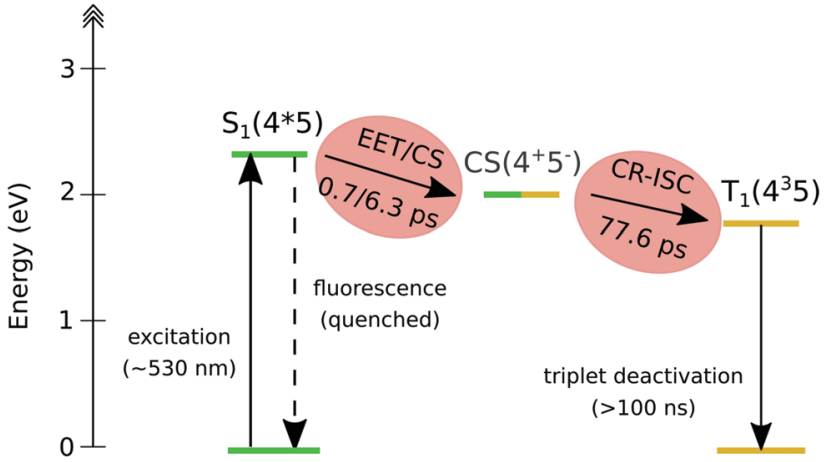

Scheme 2 Schematic representation of the decay pathway of dyad 3 upon photoexcitation of the Nile Red moiety.

occurs, triplet formation is not usually observed below the nanosecond timescale. ${ }^{1,75-80}$ Our results suggest that the mechanism of formation of the fullerene triplet in dyad 3 is related to fast electron transfer (charge separation) and back electron transfer (recombination) involving the frontier orbitals of the Nile Red and $\mathrm{C}_{60}$ moieties. Charge recombination in dyad 3 seems to rapidly produce the fullerene triplet in a preferential way with respect to the fullerene singlet. The mechanism that we envisage is the so-called radical-pair intersystem crossing (RP-ISC), ${ }^{2,4}$ i.e. a long-distance charge separation, followed by a singlet/triplet state mixing and, eventually, a charge recombination, as schematically resumed in Scheme 2. The Rehm-Weller analysis performed on this donor/acceptor dyad confirmed that the charge separation process is thermodynamically allowed for three of the four conformers singled out by the computational screening (see $\mathrm{ESI} \dagger)$.

The spectral range covered by our transient setup (up to $750 \mathrm{~nm}$ ) does not allow to check for the presence of the fullerene anion, which is expected to feature a peak at around $1000 \mathrm{~nm} .{ }^{81}$ The results obtained by the spectroelectrochemistry measurements on dyad 3 highlight that the formation of a radical pair $\mathrm{NR}^{+}-\mathrm{C}_{60}{ }^{-}$would induce a decreased absorption at about $540 \mathrm{~nm}$ and the rise of a positive band peaked at about 600-620 nm, besides a small increased absorption both in the 400-450 $\mathrm{nm}$ and in the near IR spectral ranges. Since electron transfer would occur upon photoexcitation of the sample, we do not expect to see, in the transient spectra, variations of intensity in the bleaching region in response to charge separation, while, in principle, all the positive signals observed in the spectroelectrochemistry difference spectra should appear also in the pump-probe difference spectra, at least in a certain time window. Unfortunately, the main positive band associated with charge separation, peaked at about $600 \mathrm{~nm}$, is superimposed with the negative intense stimulated emission signal (see Fig. S16, ESI $\dagger$ ). This, together with the likely very short lifetime of the CS state, probably hampers the observation of the CS state itself in the pump-probe spectra. Nevertheless, the observation of triplet formation on a much faster timescale than expected in case of FRET strongly suggests that charge separation and recombination are essential in order to justify 
the kinetics of triplet formation for the dyad in both toluene and chloroform.

\section{Conclusions}

We reported the synthesis and the electrochemical and photophysical characterization of a Nile Red/Calix[4]arene/ $\mathrm{C}_{60}$ donor/ bridge/acceptor dyad where the donor and acceptor moieties are grafted to the central scaffold through flexible linkers. The properties of the dyad were compared with the reference isolated donor and acceptor. Steady-state optical spectra show a strong quenching of the Nile Red emission and an efficient production of singlet oxygen when selectively exciting Nile Red in the dyad, suggesting a complete conversion of the photoexcited Nile Red singlet into the $\mathrm{C}_{60}$ triplet. The mechanism and dynamics of this conversion was investigated via subpicosecond transient absorption spectroscopy that, with the support of spectroelectrochemistry measurements, strongly suggests the formation of a CS state on a timescale of about a few tens of ps, followed by extremely fast charge recombination leading to the formation of the triplet localized on the $\mathrm{C}_{60}$ moiety, on a hundred ps timescale. Considering the very fast formation of the $\mathrm{C}_{60}$ triplet in dyad 3 as compared to compound $\mathbf{5}$, the most probable mechanism for intersystem crossing is the so-called radical pair ISC, which is facilitated when the donor and acceptor groups are quite far apart and weakly interacting. The flexible structure of our dyad and the presence of a quite bulky bridge can favor the decoupling of the radical pair allowing for the mixing of the ${ }^{1} \mathrm{CS}$ and ${ }^{3} \mathrm{CS}$ states. The rate of formation of the triplet state localized on $\mathrm{C}_{60}$ is high and is barely dependent on solvent polarity (on the order of $10^{10} \mathrm{~s}^{-1}$ in toluene and $5 \times 10^{9} \mathrm{~s}^{-1}$ in chloroform).

We exclude FRET followed by ISC as a possible mechanism for the formation of the $\mathrm{C}_{60}$ triplet, because of the too fast dynamics. Other mechanisms of triplet formation cannot be excluded, like SOCT-ISC or vibronically assisted ISC, ${ }^{4}$ but our spectroelectrochemical and transient absorption data, together with the conformation of our dyad, mostly support the RP-ISC mechanism. What is surprising is the speed of formation of the triplet, despite the conformational flexibility, being comparable to the SOCT-ISC mediated mechanism, typically observed in compact and orthogonal dyads.

The fast and efficient formation of the fullerene triplet in easily affordable dyads with high absorption coefficient in the visible range, in solvents of different polarity, could be of paramount importance in many applications, from the production of reactive oxygen species (photodynamic therapy) to photon upconversion.

\section{Conflicts of interest}

There are no conflicts to declare.

\section{Acknowledgements}

We dedicate this paper to Concepció Rovira and Jaume Veciana, with gratitude for their contribution in the field of advanced functional materials and for their collaborative and friendly enthusiasm. The work in Parma benefited from the equipment and support of the COMP-HUB Initiative, funded by the "Departments of Excellence" program of the Italian Ministry for Education, University and Research (MIUR, 2018-2022), and from the HPC (High Performance Computing) facility of the University of Parma, Italy. F. T. acknowledges funding from the European Union's Horizon 2020 research and innovation program under Grant Agreement No. 812872 (TADFlife). M. D. D. and S. D. acknowledge European Union's Horizon 2020 research and innovation program under grant agreement n. 871124 Laserlab-Europe. The "Centro Interfacoltà di Misure" (CIM) of the University of Parma is acknowledged for use of their NMR and mass spectrometers. University of Bologna is also gratefully acknowledged.

\section{Notes and references}

1 D. J. Gibbons, A. Farawar, P. Mazzella, S. Leroy-Lhez and R. M. Williams, Photochem. Photobiol. Sci., 2020, 19, 136-158.

2 Y. Hou, X. Zhang, K. Chen, D. Liu, Z. Wang, Q. Liu, J. Zhao and A. Barbon, J. Mater. Chem. C, 2019, 7, 12048-12074.

3 A. Aster, C. Rumble, A.-B. Bornhof, H.-H. Huang, N. Sakai, T. Šolomek, S. Matile and E. Vauthey, Chem. Sci., 2021, 12, 4908-4915.

4 D. Sasikumar, A. T. John, J. Sunny and M. Hariharan, Chem. Soc. Rev., 2020, 49, 6122-6140.

5 J. P. Fouassier and J. Lalevée, Photoinitiators for Polymer Synthesis, Wiley-VCH Verlag GmbH \& Co. KGaA, Weinheim, Germany, 2012.

6 X. Zhao, J. Liu, J. Fan, H. Chao and X. Peng, Chem. Soc. Rev., 2021, 50, 4185-4219.

7 P. Bharmoria, H. Bildirir and K. Moth-Poulsen, Chem. Soc. Rev., 2020, 49, 6529-6554.

8 T. J. Penfold, F. B. Dias and A. P. Monkman, Chem. Commun., 2018, 54, 3926-3935.

9 Z. Wang and J. Zhao, Org. Lett., 2017, 19, 4492-4495.

10 J. Verhoeven, J. Photochem. Photobiol., C, 2006, 7, 40-60.

11 Z. E. X. Dance, S. M. Mickley, T. M. Wilson, A. B. Ricks, A. M. Scott, M. A. Ratner and M. R. Wasielewski, J. Phys. Chem. A, 2008, 112, 4194-4201.

12 A. Karimata, S. Suzuki, M. Kozaki, K. Kimoto, K. Nozaki, H. Matsushita, N. Ikeda, K. Akiyama, D. Kosumi, H. Hashimoto and K. Okada, J. Phys. Chem. A, 2014, 118, 11262-11271.

13 M. A. Filatov, S. Karuthedath, P. M. Polestshuk, H. Savoie, K. J. Flanagan, C. Sy, E. Sitte, M. Telitchko, F. Laquai, R. W. Boyle and M. O. Senge, J. Am. Chem. Soc., 2017, 139, 6282-6285.

14 K. Chen, W. Yang, Z. Wang, A. Iagatti, L. Bussotti, P. Foggi, W. Ji, J. Zhao and M. Di Donato, J. Phys. Chem. A, 2017, 121, 7550-7564.

15 Y. Hou, T. Biskup, S. Rein, Z. Wang, L. Bussotti, N. Russo, P. Foggi, J. Zhao, M. Di Donato, G. Mazzone and S. Weber, J. Phys. Chem. C, 2018, 122, 27850-27865. 
16 D. Liu, A. M. El-Zohry, M. Taddei, C. Matt, L. Bussotti, Z. Wang, J. Zhao, O. F. Mohammed, M. Di Donato and S. Weber, Angew. Chem., 2020, 132, 11688-11696.

17 M. T. Colvin, A. B. Ricks, A. M. Scott, D. T. Co and M. R. Wasielewski, J. Phys. Chem. A, 2012, 116, 1923-1930.

18 E. A. Weiss, M. A. Ratner and M. R. Wasielewski, J. Phys. Chem. A, 2003, 107, 3639-3647.

19 G. P. Wiederrecht, W. A. Svec, M. R. Wasielewski, T. Galili and H. Levanon, J. Am. Chem. Soc., 2000, 122, 9715-9722.

20 C. B. Kc, G. N. Lim, V. N. Nesterov, P. A. Karr and F. D’Souza, Chem. - Eur. J., 2014, 20, 17100-17112.

21 F. Scarel, C. Ehli, D. M. Guldi and A. Mateo-Alonso, Chem. Commun., 2013, 49, 9452.

22 T. Okada, I. Karaki, E. Matsuzawa, N. Mataga, Y. Sakata and S. Misumi, J. Phys. Chem., 1981, 85, 3957-3960.

23 R. M. Williams, J. M. Zwier and J. W. Verhoeven, J. Am. Chem. Soc., 1995, 117, 4093-4099.

24 M. A. Filatov, S. Karuthedath, P. M. Polestshuk, S. Callaghan, K. J. Flanagan, M. Telitchko, T. Wiesner, F. Laquai and M. O. Senge, Phys. Chem. Chem. Phys., 2018, 20, 8016-8031.

25 C. Hippius, I. H. M. van Stokkum, M. Gsänger, M. M. Groeneveld, R. M. Williams and F. Würthner, J. Phys. Chem. C, 2008, 112, 2476-2486.

26 N. Vân Anh, F. Schlosser, M. M. Groeneveld, I. H. M. van Stokkum, F. Würthner and R. M. Williams, J. Phys. Chem. C, 2009, 113, 18358-18368.

27 I. Tosi, B. Bardi, M. Ambrosetti, E. Domenichini, A. Iagatti, L. Baldini, C. Cappelli, M. Di Donato, F. Sansone, C. Sissa and F. Terenziani, Dyes Pigm., 2019, 171, 107652.

28 B. Bardi, I. Tosi, F. Faroldi, L. Baldini, F. Sansone, C. Sissa and F. Terenziani, Chem. Commun., 2019, 55, 8098-8101.

29 A. Issac, R. Hildner, C. Hippius, F. Würthner and J. Köhler, ACS Nano, 2014, 8, 1708-1717.

30 S. Shinkai, Tetrahedron, 1993, 49, 8933-8968.

31 G. Pognon, J. A. Wytko, P. D. Harvey and J. Weiss, Chem. Eur. J., 2009, 15, 524-535.

32 I. Tosi, M. Segado Centellas, E. Campioli, A. Iagatti, A. Lapini, C. Sissa, L. Baldini, C. Cappelli, M. Di Donato, F. Sansone, F. Santoro and F. Terenziani, ChemPhysChem, 2016, 17, 1686-1706.

33 A. Arduini, M. Fabbi, M. Mantovani, L. Mirone, A. Pochini, A. Secchi and R. Ungaro, J. Org. Chem., 1995, 60, 1454-1457.

34 C. Hippius, I. H. M. van Stokkum, E. Zangrando, R. M. Williams, M. Wykes, D. Beljonne and F. Würthner, J. Phys. Chem. C, 2008, 112, 14626-14638.

35 C. Hippius, I. H. M. van Stokkum, E. Zangrando, R. M. Williams and F. Würthner, J. Phys. Chem. C, 2007, 111, 13988-13996.

36 P. S. Baran, R. R. Monaco, A. U. Khan, D. I. Schuster and S. R. Wilson, J. Am. Chem. Soc., 1997, 119, 8363-8364.

37 S. Shao, H. B. Gobeze, V. Bandi, C. Funk, B. Heine, M. J. Duffy, V. Nesterov, P. A. Karr and F. D'Souza, ChemPhotoChem, 2020, 4, 68-81.

38 A. Iagatti, L. Cupellini, G. Biagiotti, S. Caprasecca, S. Fedeli, A. Lapini, E. Ussano, S. Cicchi, P. Foggi, M. Marcaccio, B. Mennucci and M. Di Donato, J. Phys. Chem. C, 2016, 120, 16526-16536.
39 D. Gust, T. A. Moore and A. L. Moore, J. Photochem. Photobiol., B, 2000, 58, 63-71.

40 R. Ziessel, B. D. Allen, D. B. Rewinska and A. Harriman, Chem. - Eur. J, 2009, 15, 7382-7393.

41 H. Ünlü and E. Okutan, Dyes Pigm., 2017, 142, 340-349.

42 F. Sansone, S. Barboso, A. Casnati, M. Fabbi, A. Pochini, F. Ugozzoli and R. Ungaro, Eur. J. Org. Chem., 1998, 897-905.

43 C. Bruno, I. Doubitski, M. Marcaccio, F. Paolucci, D. Paolucci and A. Zaopo, J. Am. Chem. Soc., 2003, 125, 15738-15739.

44 C. Bruno, R. Benassi, A. Passalacqua, F. Paolucci, C. Fontanesi, M. Marcaccio, E. A. Jackson and L. T. Scott, J. Phys. Chem. B, 2009, 113, 1954-1962.

45 C. Amatore and C. Lefrou, J. Electroanal. Chem., 1992, 324, 33-58.

46 L. Mottier, Antigona, University of Bologna, Bologna, Italy, 1999.

47 S.-M. Lee, M. Marcaccio, J. A. McCleverty and M. D. Ward, Chem. Mater., 1998, 10, 3272-3274.

48 P. L. Gentili, M. Mugnai, L. Bussotti, R. Righini, P. Foggi, S. Cicchi, G. Ghini, S. Viviani and A. Brandi, J. Photochem. Photobiol., A, 2007, 187, 209-221.

49 I. H. M. van Stokkum, D. S. Larsen and R. van Grondelle, Biochim. Biophys. Acta, Bioenerg., 2004, 1657, 82-104.

50 J. J. Snellenburg, S. P. Laptenok, R. Seger, K. M. Mullen and I. H. M. van Stokkum, J. Stat. Softw., 2012, 49, 1-22.

51 K. M. Mullen and I. H. M. van Stokkum, J. Stat. Softw., 2007, 18, $1-5$.

52 E. R. Henry and J. Hofrichter, Methods Enzymol., 1992, 210, 129-192.

53 T. A. Halgren, J. Comput. Chem., 1996, 17, 490-519.

54 T. A. Halgren, J. Comput. Chem., 1996, 17, 520-552.

55 T. A. Halgren, J. Comput. Chem., 1996, 17, 553-586.

56 T. A. Halgren and R. B. Nachbar, J. Comput. Chem., 1996, 17, 587-615.

57 T. A. Halgren, J. Comput. Chem., 1996, 17, 616-641.

58 PCmodel v. 10.0, www.serenasoft.com.

59 M. J. Frisch, G. W. Trucks, H. B. Schlegel, G. E. Scuseria, M. A. Robb, J. R. Cheeseman, G. Scalmani, V. Barone, G. A. Petersson, H. Nakatsuji, X. Li, M. Caricato, A. V. Marenich, J. Bloino, B. G. Janesko, R. Gomperts, B. Mennucci, H. P. Hratchian, J. V. Ortiz, A. F. Izmaylov, J. L. Sonnenberg, D. Williams-Young, F. Ding, F. Lipparini, F. Egidi, J. Goings, B. Peng, A. Petrone, T. Henderson, D. Ranasinghe, V. G. Zakrzewski, J. Gao, N. Rega, G. Zheng, W. Liang, M. Hada, M. Ehara, K. Toyota, R. Fukuda, J. Hasegawa, M. Ishida, T. Nakajima, Y. Honda, O. Kitao, H. Nakai, T. Vreven, K. Throssell, J. A. Montgomery, J. E. Peralta, F. Ogliaro, M. J. Bearpark, J. J. Heyd, E. N. Brothers, K. N. Kudin, V. N. Staroverov, T. A. Keith, R. Kobayashi, J. Normand, K. Raghavachari, A. P. Rendell, J. C. Burant, S. S. Iyengar, J. Tomasi, M. Cossi, J. M. Millam, M. Klene, C. Adamo, R. Cammi, J. W. Ochterski, R. L. Martin, K. Morokuma, O. Farkas, J. B. Foresman and D. J. Fox, Gaussian 16, Revision B.01, Wallingfor CT, 2016. 
60 J.-D. Chai and M. Head-Gordon, Phys. Chem. Chem. Phys., 2008, 10, 6615 .

61 J. Tomasi, B. Mennucci and R. Cammi, Chem. Rev., 2005, 105, 2999-3094.

62 M. Maggini, G. Scorrano and M. Prato, J. Am. Chem. Soc., 1993, 115, 9798-9799.

63 J. F. Deye, T. A. Berger and A. G. Anderson, Anal. Chem., 1990, 62, 615-622.

64 J. P. Hare, H. W. Kroto and R. Taylor, Chem. Phys. Lett., 2013, 589, 57-60.

65 R. K. Dubey, T. Kumpulainen, A. Efimov, N. V. Tkachenko and H. Lemmetyinen, Eur. J. Org. Chem., 2010, 3428-3436.

66 R. M. Williams, M. Koeberg, J. M. Lawson, Y.-Z. An, Y. Rubin, M. N. Paddon-Row and J. W. Verhoeven, J. Org. Chem., 1996, 61, 5055-5062.

67 D. M. Guldi and M. Prato, Acc. Chem. Res., 2000, 33, 695-703.

68 Y. P. Sun, P. Wang and N. B. Hamilton, J. Am. Chem. Soc., 1993, 115, 6378-6381.

69 R. W. Redmond and J. N. Gamlin, Photochem. Photobiol., 1999, 70, 391-475.

70 F. Prat, C. Martí, S. Nonell, X. Zhang, C. S. Foote, R. González Moreno, J. L. Bourdelande and J. Font, Phys. Chem. Chem. Phys., 2001, 3, 1638-1643.

71 C. Bruno, M. Marcaccio, D. Paolucci, C. Castellarin-Cudia, A. Goldoni, A. V. Streletskii, T. Drewello, S. Barison,
A. Venturini, F. Zerbetto and F. Paolucci, J. Am. Chem. Soc., 2008, 130, 3788-3796.

72 D. Dubois, K. M. Kadish, S. Flanagan, R. E. Haufler, L. P. F. Chibante and L. J. Wilson, J. Am. Chem. Soc., 1991, 113, 4364-4366.

73 G. Valenti, M. Iurlo, R. M. Claramunt, G. Accorsi, F. Paolucci, M. Á. Farrán and M. Marcaccio, ChemElectroChem, 2018, 5, 985-990.

74 R. B. Weisman, K. D. Ausman, A. F. Benedetto and D. A. Samuels, Proc. SPIE, 1997, 3142, 26-35.

75 J. T. Buck, A. M. Boudreau, A. DeCarmine, R. W. Wilson, J. Hampsey and T. Mani, Chem, 2019, 5, 138-155.

76 P. K. Poddutoori, Y. E. Kandrashkin, C. O. Obondi, F. D'Souza and A. van der Est, Phys. Chem. Chem. Phys., 2018, 20, 28223-28231.

77 I. R. Gould, J. A. Boiani, E. B. Gaillard, J. L. Goodman and S. Farid, J. Phys. Chem. A, 2003, 107, 3515-3524.

78 P. C. Y. Chow, S. Albert-Seifried, S. Gélinas and R. H. Friend, Adv. Mater., 2014, 26, 4851-4854.

79 E. G. Petrov, B. Robert, S. H. Lin and L. Valkunas, Biophys. J., 2015, 109, 1735-1745.

80 R. M. Williams, H.-C. Chen, D. Di Nuzzo, S. C. J. Meskers and R. A. J. Janssen, J. Spectrosc., 2017, 1-16.

81 T. Kato, T. Kodama, T. Shida, T. Nakagawa, Y. Matsui, S. Suzuki, H. Shiromaru, K. Yamauchi and Y. Achiba, Chem. Phys. Lett., 1991, 180, 446-450. 